\title{
Applying knowledge management to planning joint-use facilities: the ImaginOn library and theater
}

Deborah E. Swain and Patrick Roughen

\begin{abstract}
Purpose - This paper aims to describe how knowledge management (KM) in planning can support the sustainability of innovation in a hybrid, joint-use facility. The case study research studies ImaginOn, a 15 year-old children's library and theater for young people in Charlotte, NC.
\end{abstract}

Design/methodology/approach - This research used KM model analysis of qualitative data about tacitexplicit knowledge, intellectual capital (IC) and cognitive modes of collaboration. Both historic documents and primary data (from field study observations, interviews and a questionnaire) were analyzed for informal KM practices. Semi-structured and unstructured interview questions about innovation were used.

Findings - This study found evidence of tacit knowledge sharing, the growth of $I C$ and the operationalization of collaboration to promote innovation. Although traditional KM terms were not used by staff, an integrated model framework demonstrates how KM practices promote innovation in planning joint-use facilities.

Practical implications - Although a study of a diverse cultural collaboration rather than two libraries, the $K M$ practices that supported innovation and collaboration in this hybrid, joint-use facility might be applied to libraries. Future KM model research on joint-use organizations could investigate merged businesses, government programs and non-profits.

Social implications - The library and theater institutions in ImaginOn impact the lives of children and parents in meaningful ways that support community understanding, art, diversity and social interaction.

Originality/value - Research on joint-use libraries began in the 1960s. This case study provides unique model analysis of KM practices in a hybrid, joint-use facility (a library and theater). The innovative success and sustainability of ImaginOn illustrates the application of KM for strategic planning and aligning $I C$ and business assets.

Keywords Innovation, Tacit knowledge, Knowledge management, Intellectual capital, Collaboration, Joint-use

Paper type Research paper

\section{Introduction}

How might innovation be sustained by knowledge management (KM) when organizations from different cultures are merged? For evidence we looked at joint-use library facilities, which seemed to demonstrate KM without formally naming processes and activities as KM practices. After early review of examples of innovation, we were intrigued by a merger that involved a non-library organization with a different culture. Thus, ImaginOn was chosen for case study research because it is a joint-use facility where two diverse organizations, a public library for youth and a children's theater, joined as one organization to share a space and assets. We found that innovation in planning has helped sustain this hybrid, joint-use facility in Charlotte, NC for over 15 years.
Deborah E. Swain and Patrick Roughen are based at theSchool of Library and Information Sciences, North Carolina Central University, Durham, North Carolina, USA.

Received 22 August 2020 Revised 22 November 2020 22 January 2021 Accepted 28 February 2021

Maryann O'Keeffe, Frank Mendoza and Melanie Huggins, current and past Charlotte Mecklenburg Library staff; Teresa Abok and Bijaya Sharma, Masters of Information Science (MIS) graduate assistants at NC Centra University; and Dr. Paul Solomon, research advisor and mentor at UNC-Chapel Hill and the University of South Carolina. 
What was behind the long-term success? An early review of the operationalization of collaboration and tacit and explicit knowledge sharing seemed to suggest the promotion and growth of intellectual capital (IC) at ImaginOn. Research was designed to investigate the impact of KM on continued operations and innovative changes over 15 years. KM practices were defined using structured models for qualitative data collection and analysis. We hypothesized that KM practices involving tacit knowledge, IC and collaboration may support sustained innovation in strategic planning and that $\mathrm{KM}$ models might be integrated into one framework for practical consideration (Dalkir, 2017).

\subsection{Background: ImaginOn history and development}

The history of ImaginOn began when the executive directors of the Charlotte public library system and the city's Children's Theater shared concerns about facility space and parking problems downtown. Land had been purchased for a library, so a collaborative core team of planners came together from the two organizations to plan and build what would become ImaginOn. The team defined a joint mission and vision to make the facility a destination location for parents and children. Not just a library or a theater, the hybrid, joint-use facility came to serve the Charlotte area with creative, innovative programs and sustained operations to bring children's stories to life.

The joint-use facility was officially dedicated in 2005 as a collaborative venture by the Charlotte Mecklenburg Library (CML) and the Children's Theater of Charlotte (CTC). It was named "ImaginOn" (the full name of the institution is "ImaginOn: The Joe and Joan Martin Center"). Both professional and community tangible resources were used to develop the facility and to define the management of intangible knowledge, strategic planning and marketing. The alignment of financial assets and IC assets occurred in the beginning.

Tangible assets: CML owned the land upon which the joint-use facility was built. The children's theater housed both a theater and a playhouse. As a joint-use facility, ImaginOn came to serve about 300,000 people a year with these designated spaces:

- Spangler library, a branch of the CML for children up to age 11, parents and caregivers (with books and multimedia resources);

- The teen loft for children aged 10-18 (innovative space with young adult books and materials);

- The block for pre-teens aged 7-11 (with LEGO $®$ tables, computer software and selfdirected activity support);

- Studio i for young adults (audio/video and animation multimedia production studio);

- Park Family Story Lab, the "heart" of ImaginOn, for all ages (interactive multimedia center for exploring narrative and story-telling);

- Tech central for young adults (technology to support computer programming, project development and Wi-Fi access); and

- Children's Theatre of Charlotte for all ages (with theatre education programs, a resident touring company and performances of classic productions, innovative shows, new works and inspirational events); the McColl Family Theater seats 570 seats and Wells Fargo Playhouse seats 250.

Associated administrative offices for management and staff for both CML and CTC are also in the ImaginOn facility.

Intangible assets: The facility's name was an important "first asset" that demonstrated strategic alignment through collaboration and $\mathrm{KM}$ to provide marketing power and community identity while each institution retained its own mission and values. Various 
organizations and institutions, including libraries, archives and museums, have established a "brand" name to strengthen their marketing and improve their public image (Bundy, 2008; Dilevko and Gottlieb, 2004; Doucett, 2008). A facility's architectural design and name are intangible assets that can provide a foundation for research on the alignment of financial assets and IC possibly enhancing strategic innovations. Over time the IC of human resources would contribute to ImaginOn's development and growth.

\subsection{Innovation: mission and operations}

ImaginOn was defined by an innovation-based mission to bring stories to life from the minds of children or young adults through plays or performances. Our research of historical information and later qualitative data showed that innovative solutions came from coordinated teamwork, which included:

- several activities and facility uses by the young customers (Story Lab) and the community (The Kindness Project) evolving from tacit knowledge;

- the growth of $\mathrm{IC}$ among ImaginOn staff and community supporters initiating innovative uses financial assets and new services, such as a community art displays in an area of the facility, a maker space and a vending/book store; and

- the creative branding and naming of the facility as a collaboration process by the early task force and core team, as well as continued operations defined by the board and in bi-weekly shared programming meetings.

Thus, at ImaginOn innovation seemed to come from the application of tacit knowledge, the growth of IC (Liebowitz, 2012) and the operationalization of collaboration among teams across the library and theater. Specific cross-organizational innovations were documented in program plans and post-project reviews of events discussed at shared programming planning meetings. The model-based research and analysis of KM evidence in this case study show how tacit knowledge sharing, IC growth and collaboration led to the sustaining of innovative solutions in a hybrid, joint-use facility.

\section{Literature review}

Joint-use libraries can be considered 100 years old when looking at the 19th century inclusion of public libraries in educational institutions as defined in joint-use agreements (Bundy and Amey, 2006; Bundy, 2008). As a modern phenomenon for libraries, research began in the 1960s when library systems and public schools started to share facilities to enhance communities and reduce building costs (White, 1963). By 2001, public and academic libraries were facing challenges managing joint-use operations (Imhoff, 2001). However, joint-use facilities have continued to be developed in the 21st century offering options to library administrators, communities and businesses to optimize services and spaces. In spring 2006, Library Trends was dedicated to "dual-use" libraries as edited by Sarah McNicol. Article topics included successful strategies for alliances (Dalton et al., 2006), evaluation of joint-use libraries (Bundy and Amey, 2006), personnel issues (Bauer, 2006) and examples of joint-use health libraries (Dorrington, 2006).

Research suggested that community business management and economic issues often drive the development of joint-use libraries. Concerns about funding of small, rural libraries, for example, has been the stimulus to develop joint-use facilities where budgets are restricted and access is difficult. Such joint-use solutions have been applied internationally. In the 1990s, faced with budget cuts for libraries in Australia, efforts to help rural libraries included establishing joint-uses libraries in remote areas. At a Tasmanian project in Queenstown, Australia: 
A joint use library is most appropriate in small, isolated rural centers where, with community support, the combined library can play a very active role in linking people to the world regardless of geographic location (Dunford, 2009).

The research on joint-use library facilities and the business of library management has touched upon the various agreements, architecture, programming and strategic planning. Expanding research on KM to include arts and crafts or "creative industry," a multiple casestudy analysis suggested that managers may not be aware of the importance of transferring the knowledge of craftsmen for sustainability and profit (Latilla et al., 2019). Theater stage craftsmen and acting directors in a hybrid, joint-use library facility such as ImaginOn might have tacit knowledge to share with library administrators and managers, for example.

\subsection{Joint-use facilities}

The joint-use library can also be called a combined, dual-use or partnership library. Alan Bundy defined joint-use libraries as facilities in which:

[...] two or more distinct library service providers, usually a school (library) and a public library, serve their client groups in the same building, based on an agreement that specifies the relationship between the providers (Bundy, 2008)

In 2001, Kathleen Imhoff described joint-use libraries as:

[...] two or more libraries of different types coming together to provide services in a single building operating cooperatively to provide resources, such as curriculum support, bibliographic instruction, and information literacy to the general public and/or students, faculty, and administrators in the context of inter-library collaboration (Imhoff, 2001)

Such collaborations have policy, legal and management implications, which present important issues regarding the rights of the entities and the support of sustainable innovation.

In the business management of library-based, joint-use facilities, co-location of libraries with community and education services has often occurred for budget reasons (Quinlan and Tuñón, 2004) including academic libraries partnering with public libraries. Although the type of joint-use varied and depended on local needs and opportunities, most were focused on providing library services as a strategic business plan and they were not planning to be innovative. One study of operations models and knowledge sharing in joint-use libraries noted that staff members of such libraries may require separate pay contracts from partners, but one administrator could supervise day-to-day operations and answer to a joint governing body (Robinson, 2006).

Examples of agencies co-locating together included libraries, theaters, tourist information centers, family history centers, archives, learning centers, childcare centers, universities, health services, leisure facilities, local government offices and community spaces of various kinds (Sidorow, 2012). Many joint-use facilities were developed throughout the world in colocated schools and public libraries. According to William Miller an important trend in 2000 was "for academic libraries (community college and university) or academic and public libraries to come together in a variety of ways" (Pellen and Miller, 2014). These knowledge centers played an important role in information institutions with the impact of digital technology for wired and wireless environments (Dilevko and Gottlieb, 2004). A small, rural joint-use partnership in the US (Illinois) started in 2002 demonstrated over 10 years the success of school-public library partnership from the vision of a community of users who participated in knowledge sharing of ideas and resources (Kluever and Finley, 2012).

For a joint-use facility, the impact of the partner institution on the library seemed to grow as the two collaborated and applied KM practices. The need for more research into the collaboration experiences of professionals in libraries, museums and archives was met in 
2013 with a deliberate social research study of collaboration and convergence (Duff et al., 2013). Professional librarians in Canada and New Zealand emphasized goals of serving users better, supporting scholarship and using technology when budgets are tight. Their futuristic plans included the use of digital objects and taking a holistic view of collections; however, collaboration across institutions was not easy (Duff et al., 2013).

Gathering quantitative data on joint-use libraries can be challenging. According to Susan Casstevens (2017, p. 67) the "[...] number of combined-use libraries worldwide is unknown. At least sixty-seven joint-use libraries exist within the United States. [...] Two hundred joint-use libraries operate in Canada, with one hundred and twenty in Australia. The UK listed 60 shared libraries [...] but this number may be an underestimate of libraries with joint-use components." The literature on such conventional joint-use facilities for schools and libraries shows that their numbers were once large and growing and that "[s] uccessful partnerships are guided by a well-defined agreement that governs each service the joint-use library offers to its respective patron communities" (Lawton and Lawton, 2009, p. 500). Agreements for successful joint-use governance in community organizations seem to require:

- deliberate formation of and continuous maintenance of relationship;

- a shared vision;

- mutually beneficial aspects; and

- resources to support community needs or demand (Howard et al., 2013).

Primarily early joint-use was found in public/school library facilities (Casstevens, 2017). In addition, public-academic library partnerships in Canada have varied in type of collaborations and partnerships with expanded services and robust sharing (SarjeantJenkins and Walker, 2014).

Although some hybrid, joint-use facilities have provided community centers and cultural activities in small towns (McNicol, 2006), the idea of partnering with a culture center, such as a children's theater, in a large city seems unique to ImaginOn; thus, our research is meant to provide new perspectives on innovation and collaboration stemming from KM practices. In general, joint-use libraries are defined as partnerships established to provide different library services in a shared facility (Matthews, 2008) and they are prevalent. Sometimes libraries can be community centers, such as the Hoover Public Library in Alabama, which offers live theater, musical entertainment, art exhibits and technology labs (www.hooverlibrary.org/about) and has been setting various experience goals for patrons since 1983. However, there are few hybrid joint-use facilities, such as ImaginOn that serve children and young adults. Examples of diverse joint-use facility efforts are Port Discovery in Baltimore (www.portdiscovery.org), Port Discover in Elizabeth City, NC (www.portdiscover. org), children's services in the Enoch Pratt Free Library (www.prattlibrary.org/kids) in Baltimore and the Children's Museum of Houston and Institute for Family Learning, which houses a parent resources library (www.cmhouston.org). This case study examines ImaginOn to see how innovative planning in a joint-use facility might be sustained by applying informal KM.

\subsection{Models in knowledge management research}

Model analysis can be an effective method for identifying processes in different organizations and for substantiating how KM processes are being applied. One definition of a model is the "representation of the essential features of system from the perspective of the observer or participant in that system" (Dalkir, 2017, p. 522). In quantitative data analytics, formal model analysis might use causal loop diagrams, or when defining KM maturity use factorial analysis and structural equation modeling (Marques et al., 2019). Simulation 
modeling can be used to develop data for decision making. An informal methodology in qualitative data analytics may use examples and applications to model an accurate representation of a process.

Researchers have identified KM enablers that impact success for business processes in models of infrastructural and organizational capabilities (Mills and Smith, 2011). One case study of an international bank, where knowledge was shared and reused, identified a KM approach, framework and ontology that supports a dynamic, continuous business process architecture; they started with a model of the object-based Riva business process architecture (BPA) method that defines domain, identifies entities, classifies units of work, diagrams case processes and applies heuristics (Sabri and Odeh, 2019). Their knowledgebased BPA approach led to a KEOntoBPA model and innovative processes to support sustainable competitive advantage (SCA). Also, their research enhanced KM's central position in the process of innovation, decision-making and organizational learning/renewal (Earl, 2001) by including the facilitators that stimulate knowledge creation (Sabri and Odeh, 2019). To effectively understand sustainability and development may require new KM models (Klingenberg and Rothberg, 2020).

Looking especially at KM in a small and medium enterprise (SME), researchers have found that using a KM system can create opportunities to lower cost, increase user-friendly or user experience (UX)-centered interactions, and be more effective; they recommend using KM tools and practices (Setiyani and Ramadhan, 2020). Investigating different configurations of $\mathrm{IC}$ and $\mathrm{KM}$ practices, researchers have found that IC levels may predict innovation potential; KM also can help leverage the IC and knowledge potential to improve performance (Hussinki et al., 2017).

One of the more useful models is the Skandia IC Navigator model of IC and organizational capital (Edvinsson and Malone, 1997). The updated Skandia Navigator model (Wall et al., 2004) for IC data analysis was useful when reviewing evidence of innovation and KM processes. Applying the Skandia IC Navigator model of intellectual and organizational capital (Edvinsson and Malone, 1997), researchers can analyze two significant types of IC applications: innovation and process development. Through structure and processes, an organization plays many roles. Originally used to compare book value to the market value of an enterprise, the Navigator model has been enhanced to include IC that is based in social, educational, cultural and creative activities. This research used the Navigator model (Wall et al., 2004) for IC data analysis and other models to analyze the impact of KM practices related to tacit knowledge and collaboration on innovation at ImaginOn. We investigated how IC might grow during the operationalization of collaboration and the structured use of tacit and explicit knowledge sharing to promote innovation.

\subsection{Innovation and knowledge management in libraries}

Innovation can be defined as applying original and effective solutions to problems so that something "new" is noticed by society or the customers in a market. As Kimiz Dalkir (2017) has explained, "Innovation is a new idea applied to initiating or improving a product, process, or service (p. 519)." Furthermore, although all innovations involve change, not all changes reflect innovation through creativity, new ideas, or significant improvements. Research on "open innovation" in organizations examines interactions with external knowledge to accelerate internal innovation and to impact the design of KM practices and implementation (Chesbrough and Crowther, 2006; Wu and Hu, 2018). Thus, crossing cultural boundaries between firms and industries may be a business strategy to enhance innovation.

In $\mathrm{KM}$ research, innovation is often considered an objective for a business especially a learning organization, and it is usually based on accumulated experience. In comparison, creativity can depend on new contexts or perspectives, but innovation is often part of new 
knowledge and new connections in existing knowledge (Dalkir, 2017). In an evolving learning environment, new knowledge comes from innovation and is spread or shared throughout an organization as knowledge assets that can be tangible or IC that is intangible. The three main sources of intangible knowledge assets are (Lev, 2001):

1. discovery or innovation;

2. organizational practices; and

3. human resources.

In analysis of the dynamic capabilities of innovation and impact from performance, learning can be negatively impacted by previous discoveries or patents where there is no knowledge diversity (Chen et al., 2017). However, collaboration as found in joint-use ventures remains an important strategy for fostering innovation capability, improving innovation performance and increasing knowledge diversity.

Without using the term "KM" in libraries, KM concepts are supported although there can be resistance. Tools seem to need to be user-friendly or center on the UX of librarians. For example, when individual reference librarians collaborate with their colleagues and share their collective knowledge, service can improve with KM. Some researchers have suggested that using a KM tool that captures and stores communal knowledge for future use is beneficial (Ralph and Ellis, 2009). However, impact from the use of KM in libraries can create barriers and divide the library culture even when decision-making and efficiency improve (Ralph and Tijerino, 2009). Therefore, a knowledge-sharing culture with seniormanagement support seems imperative for KM to be part of library operations. In 2009 reference librarians did not seem supportive of $\mathrm{KM}$ and knowledge tools, but catalogers did feel rewarded and made use of KM tools as part of their natural workflow (Ralph and Tijerino, 2009).

Innovation can depend on context as noted about small, rural joint-use projects in a funding and governance report to Australian school-community libraries by T. Lawson and M. Barry (2001). The school community or joint-use libraries in south Australia "received international recognition for the success of the model and for the innovative nature of the services provided to small rural communities" (Lawson and Barry, 2001). Similarly in New Zealand, joint-use libraries were found to have critical success factors that matched successful international efforts for joint-use libraries, but their dependence on volunteers was stronger in New Zealand (Matthew, 2008). In a case study of a joint-use library in Victoria, Australia, the Wangaratta Library. The "original vision, the methods of implementation, consolidation of services, community attitudes and a description of the value-added services of the venture" enhanced educational resources (Richmond and Twyford, 2012). As the researchers concluded, shared vision, commitment to lifelong learning, flexible staff and seamless service contributed to the joint-use library's sustaining success through innovations.

Innovation as supported by KM has not been researched in depth concerning libraries and sustained joint-use library facilities. However, in KM studies of companies, the use of tacit knowledge has been researched as it is used by innovative enterprises and was found to be a source of opportunity and potential for discovery and creativity (Alwis and Hartmann, 2008). Innovation in planning can, like reuse, be part of a business strategy (Dalkir, 2017). Overall, the importance of KM in libraries is summarized by Richard Rubin (2016, p. 396): "Like other information professions [librarianship] values knowledge in an instrumental role in improving individual and organizational growth, health and productivity." Innovations from technology, such as the web, have changed library "discovery" interfaces, for example (Rubin, 2016). However, at what level and how do librarians value innovations supported by $\mathrm{KM}$ practices and processes?

As Marina du Plessis (2007) said about KM and innovation: innovation can be defined as "the creation of new knowledge and ideas to facilitate new business outcomes, aimed at 
improving internal business processes and structures and to create market driven products and services." Such new business outcomes might support sustainability in a joint-use facility. Innovation can include both radical and incremental innovations. According to du Plessis (2007), the major roles of KM in innovation are:

- Enables sharing and coding of tacit knowledge as a resource of innovation;

- Concerning explicit knowledge during innovation, can allow later recombination, the gathering of internal and external knowledge, and the determination of any gaps;

- Enables collaboration and knowledge sharing; and

- Manages activities during KM lifecycle (creation, gathering, sharing, leveraging of knowledge).

Thus, KM can create a culture in which knowledge is valued, identified and communicated, so that processes and program such as innovation are possible (du Plessis, 2007). In libraries, effective KM may support and protect innovations that enrich staff, patrons and stakeholders as they solve problems, plan programs and sustain operations.

For many years, research on innovative marketing and branding concepts have been applied to the promotion of libraries (Ritchie et al., 1999) and of information services and systems (Freeman and Katz, 1978). In 1982, O. Gene Norman (1982) wrote an annotated guide. Over 20 years later, Robert Matuozzi (2009) described the use of public relations "to highlight the value - or to shape the story - of the library as it relates to its users and the mission of its parent institution" (p. 138). Elisabeth Doucett (2008) has listed the basic steps for branding a library and stressed the importance of library advocates being aware that libraries face keen competition from other information providers. Mark Aaron Polger began a new Marketing Libraries Journal in 2017 with a regular section devoted to various areas of library marketing (Eva and Shea, 2018).

Although KM research has not focused on library marketing and innovation in joint-use facilities, there has been growth in KM research and education in library and information sciences. Overall, with KM emerging as a discipline in the 1990s, the library profession benefited from processes and tools that supported the management of knowledge in libraries. From 1997-2009 libraries applied philosophical theories, research systems and KM practices as they launched research studies and empirical analysis of KM tools and processes (Ralph, 2010).

Almost half of library and information science education (LIS) schools seem to have introduced KM to their curriculum by the 21st century, and most research has been interdisciplinary (Hansen et al., 1999). The multi-disciplinary early approaches, such as cognitive science and organizational science, has led to wide differences in LIS definitions and applications of KM (Dalkir, 2009). The global diffusion of KM throughout LIS has supported research and education applications in two frameworks for KM:

- codifying and building knowledge repositories; and

- applying personalization or the specialization of tacit knowledge and knowledge workers (Hansen et al., 1999; Katuscakova and Jaseckova, 2019).

In addition, applying education informatics for managing and disseminating existing knowledge to support doctoral students' research can improve student success in completing degrees (Ralph, 2012). The increased support for the challenging area of KM in LIS professions may lead to increased job opportunities and an expanded scope for professionals (Katuscakova and Jaseckova, 2019).

\subsection{Collaboration and knowledge sharing}

In higher education in England, it has been found that tensions may need to be resolved when balancing mutual interests among or between joint ventures in educational 
organizations (Ross and Woodfield, 2017). Conceptual understanding and knowledge about collaborations may include shared metaphors, such as "marriage" between partners. In addition, beyond formal leadership in collaborations, effective organizations may be impacted by social practices at the lower levels that may not be rational or strategic (Greenhalgh, 2015). One researcher declared the key to a joint-use library's success is the collaboration and cooperation between institutions (Fitzgibbons, 2000) to define:

- common goals;

- a shared vision;

- agreed-to procedures; and

- consistent policies.

$\mathrm{KM}$ to support collaboration is an on-going area of study.

Some joint-use library research has explored partnerships and collaboration arrangements and how both the identity of the library and the professional identity of librarians can be changed. A few studies have looked at how the joining of institutions "makes it possible to claim that joint use libraries may actually be regarded as a new form of library with a unique identity" (Hansson, 2006). Looking specifically at the case researched here, a limited use of KM models and practices have been explored in the study of innovation and collaboration in joint-use. The ImaginOn website once highlighted innovation: "IMAGINON: It's a Library, a Children's Theatre and so much MORE!" (Wheetly, 2016).

Libraries and community arts centers have long been identified as learning organizations. Learning organizations are also a growing aspect of business culture and information is becoming an essential resource for success and an important intangible asset. KM studies about an organization's culture provide insight into business effectiveness (Ratna et al., 2020). Research in the information technology (IT) industry by Ratna et al. (2020) suggests that $\mathrm{KM}$ can contribute to organizational effectiveness and underscores the value of culture, knowledge and collaboration as part of a coherent process. Furthermore, IC may be an essential intangible asset, but as part of $\mathrm{KM}$ practices the culture and organization can strategically align IC and financial assets for successful performance (Hussinki et al., 2017). Sharing of insights and tacit knowledge may motivate employees and promote intellectual and financial growth.

Knowledge sharing can be impacted by the size of an organization and the availability of tools. As observed in a study of wiki use and a research and development department for a software company, "few experts were known to all and could readily share their knowledge" (Skoglund, 2011); as the organization grew, the department could be divided into "power users" and "learners" who used tools such as a corporate wiki to seeks answers. Tools, such as SharePoint, have been shown to help smaller organizations provide access in realtime to information, and to improve collaboration and knowledge sharing (Khumalo and Mearns, 2019). Personal knowledge sharing of deeply imbedded, tacit knowledge may become a smaller knowledge flow as externalization and combination tasks (from the socialization, externalization, combination and internalization [SECI] model) come to depend on tools like wikis to make the knowledge visible (Beckett, 2016).

Another aspect of collaboration for joint-use facilities can involve marketing and branding or naming of the facility. In 1950 the American Marketing Association defined the word "brand" to refer to a design, symbol, logo, sign or name to identify or differentiate a product in the marketplace. Hood and Henderson (2005) found that branding was central to public library marketing plans in the UK in 2005. The definition and use of branding, for example, are based on clarifying the mission and the message an institution sends to its stakeholders about its services (Doucett, 2008). A name and brand are associated in the minds of customers and patrons with experiences and expectations about library services. 
"Brand-building" can include a catchy name, a memorable logo, attractive packaging, or the use of sound bites. Libraries must distinguish the value they represent and go beyond the image of for-profit institutions. For example, in American libraries, the "@ your library" mark was created for an American Library Association (ALA) campaign (Spalding and Wang, 2006). As many libraries now do their own personal branding, the KM of such an intellectual, non-tangible resource warrants research.

Subnum and Hariff (2011) stated that "often marketing and branding are seen by staff as a function of only the marketing department." However, as this case study of a hybrid, jointuse library suggests, marketing and branding can require the tacit knowledge and collaborative participation of both the library staff and the staff of the partner (a theater institution). In a community-based facility such as ImaginOn, "a higher social purpose" may also be part of the marketing and KM context (Koontz et al., 2006).

\subsection{Gaps in knowledge management research}

This literature review shows little KM research on innovation in joint-use libraries and nothing specifically on hybrid facilities that join organizations from different cultures. After reviewing the literature on joint-use libraries, one might ask why develop a joint-use library that provides more than library services? Why expand the functions of a library by collaborating or partnering with another institution? How can non-library partners also serve the community and increase information services? A review of college students' perceptions of information resources and libraries in 2006 made a strong case that awareness of library resources is essential to the future success of the library after it was found that the main service of libraries is still about books, and other studies suggest that library services go beyond books (Rooney-Browne, 2007). What about innovation, for example, in a joint-use library that combines theater and acting training with library and youth services? This paper explores that idea by investigating how KM has been applied to the design and development of ImaginOn in Charlotte, NC. Our research documents knowledge-sharing practices and the KM processes used to define and sustain the joint-use mission and goals. We expected to find examples about how to work with another institution and to develop an identity for the shared space in a joint-use facility. Our qualitative research and analysis was intended to show the value of $\mathrm{KM}$ and a structured process when planning an innovative, cultural center in a joint-use facility. That is, the hypothesis of this KM-focused research was that continued success and innovation may grow out of successful KM practices, such as sharing design knowledge and collaborating to support business, marketing and sustained operations. Our research analysis of qualitative data is rooted in the use of different types of models.

\section{Methodology}

The model-based research methodology presented here used KM models to examine the development and sustained operation of ImaginOn. Mainly models about three primary aspects to the management of knowledge were used:

- evolution from sharing tacit and explicit knowledge;

- developing and nurturing IC; and

- supporting collaboration.

An informal methodology in qualitative data analytics can use examples and applications to model an accurate representation of a process. We used qualitative methods for analysis and to model KM processes at the ImaginOn to find any evidence of KM practices impacting innovation and collaboration in a joint-use facility. We focused on the structured use of tacit and explicit knowledge sharing, the growth of $\mathrm{IC}$ and the operationalization of collaboration to look for examples of $\mathrm{KM}$ supported innovation in this case study. Hypothetically, we thought our findings might lead to multiple models forming an integrated 
theoretical framework for using KM to promote sustainable innovations. That is, by integrating the evidence-based models that were collected from qualitative data and analyzed, a resulting KM framework might be used both to study collaboration in joint-use efforts and to understand how to promote innovation. A practical implication was that an integrated KM framework might have prescriptive uses within and between organizations (Dalkir, 2017, p. 66).

\subsection{Model of tacit and explicit knowledge sharing}

The SECI model demonstrates that "explicit knowledge without tacit insight quickly loses its meaning. Knowledge is created through interactions between tacit and explicit knowledge and not from either tacit or explicit knowledge alone" (Alwis and Hartmann, 2008, p. 134). The SECl model is an iterative or repeating spiral of innovation moving from tacit to explicit knowledge. Figure 1 shows the SECl model of knowledge conversion (Roughen and Swain, 2019); adapted from Nonaka and Takeuchi (1995), who studied how Japanese companies succeeded in creativity and innovation. Knowledge is produced as the team or project goes through conversion and interaction during four stages: SECI. In a review of the use of SECI from 1995 to 2018, researchers found exponential growth in the use of the SECI model and both acceptability and applicability continuing; however, knowledge sharing enablers seemed required by organizations and organizations needed to pay close attention to the beginning of the cycle and "socialization" for effective KM (Adesina and Ocholla, 2019).

\subsection{Model of intellectual capital}

The Skandia navigator model was used for analysis of the development and nurturing of IC. The hierarchy of the navigator model suggested how overall "organizational capital" assets can continue to contribute to marketing and sustaining the ImaginOn organization, for example (Figure 2):

Specifically, the Skandia navigator model (Wall et al., 2004) for IC data analysis was used to identify collaboration and innovation at ImaginOn. The key dimensions at the core of the navigator model are:

- Financial focus (monetary)

- Customer focus (value of customer capital, both financial and non-financial)

- Process focus (effective application of technology)

- Renewal and development (the innovative capabilities of organization)

\section{Figure 1 SECI model}

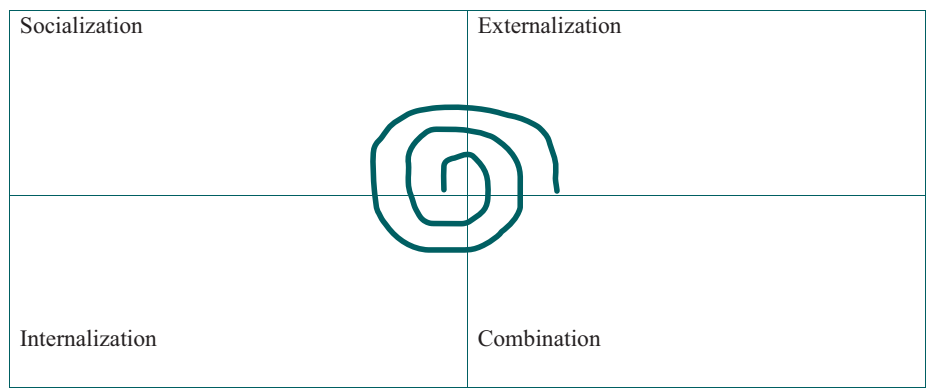

Source: Adapted from Nonaka and Takeuchi (1995) 


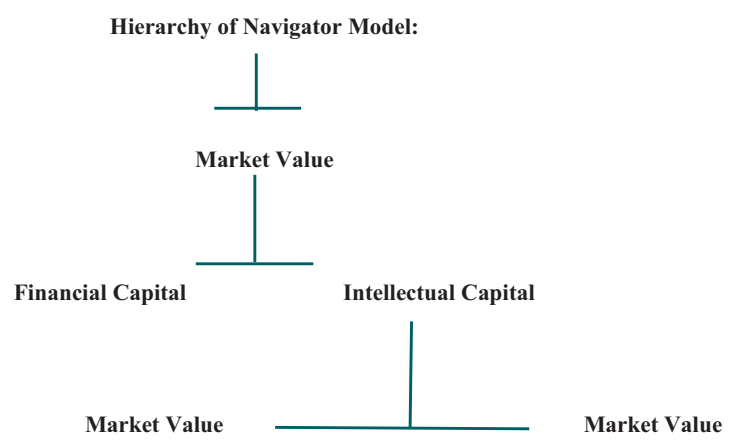

Source: Adapted Dalkir (2017)

All four are parts of a KM focus on people and human resource management that can be used to measure human capital in an organization (comparable to balanced scorecard measuring). As established in Phase One and sustained in Phase Two's field study staff interviews and survey questionnaire, data collection showed support of the four dimensions of IC at ImaginOn:

1. Focus on finances was part of the public library management system: There was a 1983 bond for library systems, and then the original development of ImaginOn came after the 1996-1999 additional bonds were passed in Charlotte to build libraries. After the 1999 bond, collaborative core team to design and plan for ImaginOn was established.

2. Customer focus was the core of the community-centered approach of a joint-use facility such as ImaginOn as it provides library information and technology to create with special interest in drama and stories. Parents join the library in planning events, bringing young children and volunteering to help improve customer service. In 2011, the "Flag of Hope" full wall mural from across NC was housed at ImaginOn.

3. Computer labs and maker-spaces supported interactive and learning activities.

4. A traditional gift shop was remodeled to make more money as an innovative change to support sustainability.

\subsection{Models of collaboration and planning}

Various barriers, issues and challenges have been predicted for joint-use library facilities and studied. Kathleen Imhoff (2001) has noted that joint-use partnerships often occur between libraries that already have experience in partnering and are built on personal relationships when people within the partnering libraries know each other. Imhoff (2001) listed nine challenges:

1. Planning

2. Governance

3. Administration and financing

4. Access to information and materials

5. The physical facility

6. Technology integration 


\section{Attitudinal factors}

8. Staffing

9. Identity

ImaginOn went beyond library services by integrating a children's library and a children's theatre into on joint use facility. In qualitative data analysis, the barriers and issues or concerns that require resolution by a collaborative group can be sorted and analyzed based on: assumptions, responses and end results (Miles and Huberman, 1994).

The qualitative data analysis methodology developed by Miles and Huberman (1994) provided a structured and replicable process for the collection and analysis of textual data. The iterative process during data analysis involved "data reduction, data display and conclusion drawing/verification" (Miles and Huberman, 1994). As a recursive or dynamic process for collecting data, analyzing and revising models and matrices, the process may involve several cycles before researchers can identify the process of finding knowledgebased resolutions and collaboration. Conclusions or recommendations may lead to generalizable processes, such as a framework for KM collaborative innovation.

Models can provide a deeper understanding of processes and a strategic roadmap for meeting KM goals (Dalkir, 2017). KM models cover processes, collaboration and innovation, which we used to examine how innovative collaboration started and was sustained for 15 years with support from KM practices. A well-known KM business model has three phases or steps for development that can be applied to KM for joint-use facility collaboration (Hansen, 2009):

- Evaluate opportunity for collaboration across business unit;

- Analyze if any of the four barriers to collaboration exist in organization; and

- Tailor solutions to resolve barriers that using collaboration enablers or combinations of the enablers.

The four potential barriers to collaboration can be summarized in a table (Dalkir, 2017) (Table 1):

In knowledge-intensive organizations, it has been suggested from a survey study that the biggest barriers to effective KM was lack of budget, executive support and time for knowledge sharing; the stakeholders surveyed suggested that knowledge sharing was a priority over creation, capture, transfer and reuse of knowledge (Mazorodze and Buckley, 2019). The need for strategic management planning was suggested as a path toward improved performance in knowledge-intensive organizations; libraries are knowledge-intensive. Another case study

\section{Table 1 Barriers to collaboration}

\begin{tabular}{|c|c|c|}
\hline No. & Name & Description \\
\hline 1 & $\begin{array}{l}\text { Not Invented } \\
\text { Here }\end{array}$ & $\begin{array}{l}\text { A motivational issue impacting confidence in } \\
\text { competence Can lead to not being willing to help or } \\
\text { share knowledge }\end{array}$ \\
\hline 2 & $\begin{array}{l}\text { Hoarding } \\
\text { Knowledge }\end{array}$ & $\begin{array}{l}\text { Knowledge seen as power, so feel takes time and } \\
\text { results in little reward when you share knowledge }\end{array}$ \\
\hline 3 & $\begin{array}{l}\text { Ineffective } \\
\text { Searching }\end{array}$ & $\begin{array}{l}\text { Unable to find information or people who can help. } \\
\text { Perhaps usable, collaboration tools or networks not } \\
\text { established }\end{array}$ \\
\hline 4 & Transfer & $\begin{array}{l}\text { People not able or trained to work together. Note: } \\
\text { may have problems sharing tacit knowledge if } \\
\text { employees have little in common, different identities } \\
\text { and do not trust }\end{array}$ \\
\hline
\end{tabular}


reviewed the potential for $\mathrm{KM}$ processes in an academic library and found that $\mathrm{KM}$ was utilized, but processes were not formalized through library policy or leadership buy-in (Sirorei and Fombad, 2019).

Leaders in organizations can include KM in strategic plans. Connecting strategic planning and KM models can involve knowledge sharing in local municipalities (Musonza and Muchaonyerwa, 2019). Considering global businesses and perspectives, a strategic management model in Russia evolved from KM methodologies and suggested uses of decision theory in the knowledge economy (Vorobyov et al., 2019). This "unified model" integrated strategic and KM methodologies in a unified process analysis, and their method of development applied iterative steps. Such an approach that used synergies from models in research analytics underscored the value of KM model analysis especially when evaluating tacit knowledge assets. Similarly, an integrated framework that applies three key $\mathrm{KM}$ elements (tacit and explicit knowledge; the creation, sharing and implementation of processes; and enablers from technology, leadership, culture and strategy) offered a guideline for analyzing successful KM practices (Dei, 2019). Furthermore, researchers reviewing KM literature have applied the soft system methodology to evaluate use of KM conceptual models by stakeholders and recommend promoting the use of actors, activities and sequential order as recommended features (Sensuse et al., 2019); usage learning improving and knowledge sharing seemed to dominate implementation.

Researching collaboration, John Smith (1994) provided a model about collective intelligence and cognitive modes as a way of thinking that identifies collaborative group tasks. Smith's (1994) framework for collective intelligence is centered on computer-aided collaboration. A group's cognitive modes (Table 2) show three basic "processing sequences:"

1. Discussion or brainstorming to externalize information and resolve conflicts.

2. Presentation, summary or demonstration of prototypes to introduce information to team members.

3. Delegation and decision-making to assign appropriate tasks or evaluations (acting on knowledge).

\section{Two research phases}

The primary research focus for our case study was about how KM and collaboration processes may support innovation. Specifically, we asked: How might innovation be sustained by KM when organizations from different cultures are merged? The joint-use facility ImaginOn provided a case study on forming and sustaining informal KM practices, collaborations and innovation. As a qualitative study, our research investigated library

\section{Table 2 Modes of collaboration template}

Modes

and sub modes Goals Kroducts Knowledge sharing

Discussion

Conflict resolution

Brainstorm

Presentation

Summary

Demo

Delegation

Source: Adapted from Smith (1994) 
management and applications of KM from data analysis based on different models and looked at business practices and planning processes.

We had two phases of research based on source materials and collecting new data on the sustainability of ImaginOn. Phase One started with data from 1990 when idea of a jointfacility was first discussed and 1999 when a core team from CML and CTC formed a task force to make plans. Continuing with qualitative data covering up to 2010, Phase One research required the collection of secondary sources, the study of historical documents and the analysis of past events to define collaboration. Major issues stemming from early concerns between CML and CTC were analyzed as barriers to collaboration. A model of cognitive modes was used to identify the collaborative processes involved in establishing the original brand name "ImaginOn," and in business marketing. Changes started in 2011 after the Future of the Library Task Force (citizens group) presented ideas and community feedback for ImaginOn.

Phase Two research on sustained operations required primary data collection to analyze the sustainability of ImaginOn and to identify continued innovations that might illustrate KM processes. Primary qualitative data was collected during a 2020 field study with the documentation of observations, staff interviews and guided tours of the rooms, spaces and labs in the facility. Information about KM applications and collaborations were collected covering several examples of innovations over 15 years. In addition, primary qualitative data was collected from semi-structured interview questionnaires distributed to administrative staff. The questions were designed to focus on potential verification of the use of tacit knowledge and collaboration: KM data about communication tools, knowledge collection, regular meetings, project reviews and personal experiences. Knowledge-based process models for the development of tacit and explicit knowledge and for knowledge sharing used to analyze the data from Phase Two could be added to the collaboration enablers from Phase One. In the conclusion, results from both phases summarize KM practices by innovative administrators and staff sustaining a joint-use facility and provide learning lessons for libraries, community organizations and businesses.

\subsection{Phase one: historical data analysis}

The idea of the joint-use children/teen's library and theater ImaginOn had a mundane origin. In 1989, there was a meeting over the lack of parking space in downtown Charlotte. Both the Executive Director of the Public Library of Charlotte and Mecklenburg County and the Executive Director of the Children's Theater of Charlotte attended. They saw the negative impact that a lack of parking had on library and theater patron access, and the idea of building a single, shared facility seemed a possible solution (Roughen, 2012, 2016).

The CML is a large library system, whose headquarters are in Charlotte, NC. The local city and county governments have significant experience with joint-use agreements. Around 1995, the City of Charlotte and Mecklenburg County created a joint-use task force including a representative of $\mathrm{CML}$ to facilitate the development of policy statements and processes for the Charlotte-Mecklenburg area. Representatives of the library sat on the task force. From the start, the joint-use facility housed both a library and a theater as co-equal partners. Over time the lease was revised, new operating agreements were negotiated and greater sharing of knowledge and responsibilities among staff was achieved.

The idea of building a children's learning center with characteristics of both a library and a theater generated early enthusiasm. Steps were taken to arrange for public funding of this enterprise using monies from a bond referendum in 1983 and additional bonds proposed and passed between 1996-1999. After the 1999 bond referendum passed, a core team was established comprised of five individuals from the $\mathrm{CML}$ and five individuals from the CTC. It would take about five years for the core team to develop a feasible plan for a jointuse library and theater. 
Due to an economic recession, there were cuts in library services that were considered devastating in the community. However, from these challenging times the CML, Mecklenburg County and community leaders in Charlotte found ways to collaborate. They shared the goal to provide Mecklenburg County residents with the resources required to be successful. In fall 2010, the Library Board of Trustees and the Board of County Commissioners appointed a citizen group called Future of the Library Task Force (2011a) to study the status of the public library. This 17-person task force included experts in business, law, education and finance and community leaders. They were charged with making recommendations for a sustainable future for the $\mathrm{CML}$, including ImaginOn.

The Future of the Library Task Force (2011b) made recommendations in the spring of 2011. Their 39 recommendations fell into four broad categories: funding, system, services and structure. With additional funding, the CML could improve services and support the citizens of the county's significant needs. Library administrative leaders and staff then worked quickly to implement the task force's recommendations. Mecklenburg County's increased funding in fiscal years 2012, 2013 and 2014 allowed the CML to extend hours at libraries and increase resources.

The leaders of the ImaginOn collaborating team changed, but the group retained a central figure, the Youth Services Director and the library provided leadership. "At various points in our history, one organization naturally took the lead because it just made sense" (Baron, 2016). Individuals, such as the Youth and Outreach Services Director of CML, retained a central role in the development of the joint-use facility. She "came on board" after the bond referendum passed in 1999 to help manage the details and see the project to its completion (Roughen, 2012). Concerning collaboration and KM, she noted that the core team worked diligently "starting to get to know each other, getting to know each other's organizations, what they did, how we were different, how we were the same" (Roughen, 2012).

Planners realized fairly early that "Children's Learning Center" seemed too remedial a concept and was an indistinct name that would not have marketing drawing power for children, youth and parents. The core team knew that they needed to develop a name and an identity for the future facility (Roughen, 2012). After four years working on the programming and design, the core team could not decide on the name for the joint-use facility (Roughen, 2012). However, they agreed that they wanted an exciting, energetic and creative name. When the team decided that they were at an impasse, they chose to seek outside help. A company, which specialized in naming, was brought in and a subcommittee of five individuals was formed. Together they decided that the name would need to appeal to children and not alienate teens. In other words, they wanted a name that was inspiring, had personality, was indicative of a desirable place to go, was aspirational, was able to be trademarked and seemed inviting to children of all ages. Also, the name had to represent a kind of fusion between the community-based CML and the artistic-driven CTC. ImaginOn was not a joint-use facility of two libraries and "both the library and the children's theater recognized a need to maintain their separate brands and visibility to potential funders as independent organizations" (Baron, 2016). The sub-committee required KM of ideas and a collaboration process to find a name that illustrated their balanced relationship.

The Youth Services Director noted that from the beginning the need for a link between "imagination" and "telling our story" that provided inspiration for innovation was apparent to the sub-committee. Nonetheless, it was difficult to come up with a name that was acceptable to both institutions and all stakeholders. Over the course of the naming collaboration, about a hundred names were suggested. The process included several reviews to eliminate about 30 names. The first list of names generated by the naming company did not include "ImaginOn." It appeared at the end of the naming process. Over 15 years, the ImaginOn name has not changed although the CML system has repeatedly been rebranded (Baron, 2016; Roughen, 2016). 
4.1.1 Model analysis. Using a qualitative data collection and analysis (social research) approach, Phase One of this study applied model analysis to historical documents and analyzed past events and issues to determine major early concerns and barriers to collaboration. We reviewed interviews, articles and project information about the joint-use facility partnering of the CML and CTC. Historical interview documents from staff and consultants along with articles, websites and publications about ImaginOn were collected and analyzed using iterative versions of summary forms and matrices to support a recursive method of study. A model of collaboration modes was used to analyze early efforts and the cognitive steps to establish ImaginOn.

The secondary qualitative data documentation that the researchers assembled was also used to define the community environment (ethnography) based on articles, interview data and previous research (Roughen, 2012). Using qualitative analysis summary forms and matrices, the researchers identified the significant issues or barriers to collaboration during the early joint-use definition process. See Appendix 1 for full list of issues analyzed in summary forms and issues matrices. With model analysis of the cognitive modes of collaboration (Smith, 1994), the researchers could demonstrate the collaborative process used to resolve issues and barriers.

Qualitative data analysis procedures from Miles and Huberman (1994) provided a structured and replicable methodology for the collection and analysis of textual data. From preliminary discussions, the researchers hypothesized that the ImaginOn project might also demonstrate cognitive modes of collaboration and an effective KM process to overcome barriers and resolve issues. Historical data on early collaboration and both semi-structured and unstructured interviews of ImaginOn staff were analyzed qualitatively using social research methods for data analysis (Wildemuth, 2017). Collaboration or a group working on a shared goal (Schrage, 1995) depends on knowledge sharing. A cognitive modes model was used to investigate if time and methods for distributing information and developing joint knowledge impacted results (Smith, 1994; Swain, 2010).

Thus, research in Phase One applied model analysis methods to demonstrate KM during the design and development of ImaginOn: the case dynamic matrix models about resolving major project issues or barriers and the model of cognitive modes in the collaborative process. A knowledge-based application of these models could possibly be integrated with Phase Two models to define a framework for creating joint-use facilities for libraries, community organizations and businesses.

4.1.2 Historical data collection. The sources for the collection of secondary qualitative, textual data included newspaper and websites, and interviews with administrators and design and development project team members. See Appendix 2 for a list of the primary task force and core team members who participated in interviews that were quoted in articles and for a table with quotations on innovation.

The ethnography and description of the customs of individual people or cultures for the ImaginOn project is based on publicly funded institutions. During the ImaginOn development project, a joint task force was created in 1995 that represented local government, the Charlotte Mecklenburg Library and the Children's Theater of Charlotte. In 1999 a core team for joint-use was formed and an external consulting group joined the project to assist with the KM of the branding and naming process.

Cultural differences between the CML and the CTC were noted during data collection. Some felt that the theatre team or CTC represented "energy, excitement and pizazz," and the CML had legitimacy, community connections, respect and technology (Block, 2007). However, the collaborating teams and sub-committees remained committed to the vision and mission of the project. Deliverables from the core team included: a mission statement, a vision and a set of core values (Kilkka, 2008): 
The mission they developed, 'bringing stories to life through extraordinary experiences that challenge, inspire and excite young minds,' blended the library and theater experiences by incorporating written, spoken, visual, and digital methods of expression. The project leadership also considered the complexities that arise when two venerated institutions maintaining their own corporate identities [collaborate] to create a seamless visitor experience (p. 92).

The mission statement represents the merged aspirations of the two organizations, CML and CTC, who had different histories, traditions and cultures, but collaborated and came together to develop a joint-use facility. In comparison to joint-use libraries merging different library services, the ImaginOn brought together heterogenous organizations. See Appendix 3 for a timeline list of significant events defining ImaginOn's early development and collaboration.

4.1.3 Barriers to collaboration. From the historical documentation, issues or barriers to jointuse implementation based on interviews were collected from project participants and sorted in summary lists for analysis. The following list from the first data collection of collaboration barriers (issues and concerns) determined the size and resources for the original ImaginOn joint-use partnership:

- Parking for downtown facilities;

- Location change for the children's library;

- Deterioration of Main Library in Charlotte; and

- Architecture and building plans (never done before).

(Appendix 1 shows full list of issues iteratively analyzed in summary forms and issues matrices.) An issues matrix can be used in qualitative data analysis to define the major barriers to collaboration (Miles and Huberman, 1994) and to illustrate a resolution process based on the use of knowledge. The matrix supports Hansen's KM management model for planning and collaboration (2009). The barriers analysis process summarizing the early development of ImaginOn lists the assumptions, responses and end results for the five major issues and concerns:

1. Parking downtown - early stimulus;

2. Policies and agreements - city, county, CML;

3. Funding - original bond referendums, budget cuts (2010);

4. Leadership - changes retained director; and

5. Marketing and branding - subcommittee, external consultant, ImaginOn decision.

Table 3 illustrates the KM management model for early collaboration to resolve issues.

We noted that when name branding is done with the assistance of external resources, such as marketing companies, limited information may be available for research because of client confidentiality. Also, when branding is done in-house, details regarding the process and any management of knowledge may not be readily attainable. Thus, data collection and $\mathrm{KM}$ research can become challenging. However, there was knowledge-based data from interviews and historical documentation available as secondary data to analyze ImaginOn's definition of itself at the beginning and use of IC. In Phase Two, a semi-structured questionnaire survey and face-to-face interviews with staff during a field study and tour were used to collect primary KM data and examples of collaboration and innovation, which enhanced historical data findings. Also, a final focus interview with ImaginOn's Planning and Partnerships Coordinator that was face-to-face on WebEx used unstructured questions (Wildemuth, 2017) designed to validate the model-based findings and continued marketing impact of the collaboration-based brand name.

$\mid$ JOURNAL OF KNOWLEDGE MANAGEMENT | 
Table 3 Early collaboration significant issues matrix

\begin{tabular}{|c|c|c|c|}
\hline Issue & Assumption & Responses & End results \\
\hline Parking downtown & $\begin{array}{l}\text { Both CML and CTC needed } \\
\text { parking spaces for customers } \\
\text { (1989) }\end{array}$ & $\begin{array}{l}\text { Shared concerns of negative } \\
\text { impact and formed core } \\
\text { planning team for joint-use }\end{array}$ & $\begin{array}{l}\text { Physical Facility: Block long } \\
\text { shared edifice designed (and } \\
\text { parking provided) }\end{array}$ \\
\hline $\begin{array}{l}\text { Policies and } \\
\text { agreements }\end{array}$ & $\begin{array}{l}\text { City of Charlotte, Mecklenburg } \\
\text { County and CML would need } \\
\text { agreements }\end{array}$ & $\begin{array}{l}\text { Use previous agreements } \\
\text { among local governments }\end{array}$ & $\begin{array}{l}\text { Task Force: around } 1995 \text { the } \\
\text { city and county created joint- } \\
\text { use task force }\end{array}$ \\
\hline Funding & $\begin{array}{l}\text { Utilize bonds (early funding } \\
\text { would be available from } 1983 \\
\text { bond) }\end{array}$ & $\begin{array}{l}\text { More bonds proposed and } \\
\text { passed from 1996-1999. } \\
\text { Following } 1999 \text { bond passage, } \\
\text { core team formed to plan joint- } \\
\text { use facility }\end{array}$ & $\begin{array}{l}\text { Sustainability: in } 2005 \text {, } \\
\text { ImaginOn dedicated. In fall } \\
\text { 2010, "Future of Library Task } \\
\text { Force" formed to plan } \\
\text { sustainable financing }\end{array}$ \\
\hline Leadership & Sharing of leadership & $\begin{array}{l}\text { Position and job changes led to } \\
\text { changes in leadership between } \\
\text { CML and CTC }\end{array}$ & $\begin{array}{l}\text { Leadership: a primary focus } \\
\text { leader retained (Higgins) }\end{array}$ \\
\hline $\begin{array}{l}\text { Identify brand name } \\
\text { and marketing }\end{array}$ & $\begin{array}{l}\text { Core team must decide on a } \\
\text { brand (name) }\end{array}$ & $\begin{array}{l}\text { After four years, no consensus } \\
\text { (impasse) }\end{array}$ & $\begin{array}{l}\text { Outside company hired to work } \\
\text { with subcommittee of core } \\
\text { team formed }\end{array}$ \\
\hline
\end{tabular}

4.1.4 Collaboration process and cognitive modes model. Using model analysis, our study analyzed interactions and evidence of cognitive modes of collaboration among CML and CTC teams during the early development of the joint-use library and theatre, ImaginOn. The design and development collaboration process illustrate cognitive modes associated with knowledge sharing.

A team-based, collective process on a project can be compared to the efforts of a single author writing a paper. Both the team's and the individual's efforts progress through specific cognitive modes (Lamott, 1994) that writers often use:

- Brainstorm ideas, scope, style, audience, purpose and structure.

- Develop an outline or first draft.

- Write a rough draft for editing.

During collaboration, a group tends to follow the same progression though the order of steps may involve feedback loops. That is, group thinking can be analyzed as a similar, collective form of intelligence involving multiple levels of interaction. Early ideas are personal, and the process is tacit and internal until ideas or an explicit draft report are shared. Individual's writing criticism may be suspended until after a completed first draft; however, collaborators seek criticism and each other's ideas to understand the group's tacit knowledge during a project.

There were several examples of cooperation and resolving issues. Specifically, the collaboration process during the naming of ImaginOn activity and sub-committee efforts provided data to illustrate the collaborative cognitive modes as shown in Table 3. The collaborative joint-use planning and branding process was evolutionary and illustrates the innovative, creative process often apparent when developing a new institution. From the beginning, the task force focused on the shared values of the two organizations. A summary of the collaborative process for naming ImaginOn and the progression of cognitive modes is shown in Table 4.

In addition, the spatial and architectural design of the joint-use facility itself was an experimental process of innovation and different models of organization were considered; for example, Baltimore's Port Discovery Children's Museum was used as a joint-use facility model for ImaginOn and for building an integrated institution with a focus on children 


\begin{tabular}{|c|c|c|c|}
\hline $\begin{array}{l}\text { Modes } \\
\text { and submodes }\end{array}$ & Goals & Products & Knowledge sharing \\
\hline Discussion & Name the facility & Different views awareness & $\begin{array}{l}\text { Dialog } \\
\text { Analysis: view in groups of } \\
30\end{array}$ \\
\hline $\begin{array}{l}\text { Conflict resolution } \\
\text { Brainstorm }\end{array}$ & & $\begin{array}{l}\text { Over } 100 \text { suggestions } \\
\text { More names generated }\end{array}$ & \\
\hline Presentation & $\begin{array}{l}\text { Introduce } \\
\text { "ImaginOn" }\end{array}$ & Group-level agreement & $\begin{array}{l}\text { Teach and inform } \\
\text { Listen, learn, question and } \\
\text { evaluate }\end{array}$ \\
\hline Summary & $\begin{array}{l}\text { Insure same } \\
\text { message received }\end{array}$ & & \\
\hline Demo & $\begin{array}{l}\text { Demonstrate use of } \\
\text { name }\end{array}$ & & \\
\hline Delegation & Assign tasks & $\begin{array}{l}\text { Solicit agreement and } \\
\text { support from artistic } \\
\text { director and others }\end{array}$ & $\begin{array}{l}\text { Tell the public } \\
\text { Listen and evaluate } \\
\text { (following newspaper article } \\
\text { and feedback) }\end{array}$ \\
\hline
\end{tabular}

(www.portdiscovery.org). Various processes of collaboration, cooperation and coming together were used; and there were numerous meetings, trips, site visits to other similar institutions, and tours of partnership facilities of various kinds, especially libraries and children's museums. The design of ImaginOn was a highly creative process, often keeping members of the core team brainstorming into the late hours of the night (Roughen, 2012). Programming and services were planned for what would become a block-long, futuristic edifice. Both the branding and naming process and the physical design effort to create innovative space also demonstrate the SECI model of knowledge development. The core team's efforts were found to evolve through the four stages: SECI for tacit and explicit knowledge in a repetitive process.

During design and development, it was noted that the Walt Disney Company was promoting imagination as a prominent theme for its products. So, during branding, the use of any variant of the word "imagination" had to avoid obvious references to the Disney brand. The "ImaginOn" name seemed appropriate with a capital "O" and generated enthusiasm on the subcommittee. "ImaginOn" was attractive to the collaborators because it suggested a place to engage in imaginative activity. Although there was concern that the uppercase version might suggest a command, the winning name with the verb-based uppercase "O" also suggested a place where a child or youth's imagination would always be "on."

The CTC artistic director approved the selection of ImaginOn as "a name that had to be defined by experience [...]. You would have to experience ImaginOn to know what it is." Furthermore, he noted that it "did not identify the space itself as a library or a theatre, but as a place where children and their families could learn, play and imagine together" (Lee, 2007).

After the selection of ImaginOn as the name for the joint-use facility, the CTC and CML announced it publicly. There was some initial criticism of the name in a local newspaper, The Charlotte Observer; however, once the public recognized that the name was unique and not associated with anything else, it seemed to be accepted by the community. Additional aspects of brand-building included design of a logo, marketing and the promotion of the joint-use library.

4.1.5 Results of historical data analysis. The qualitative data collected from the iterative development of a primary issues matrix showed that the core team, the naming 
subcommittee and administrators from CML and CTC shared knowledge and followed a collaborative process. The process demonstrated the three cognitive mode phases of:

1. discussion or brainstorming;

2. presentation, summary and demonstration; and

3. delegation and decision-making to appropriately act on shared knowledge.

Starting with sharing a concern about parking, a core planning team was formed after the 1999 bond referendum passed. With continued communications and knowledge sharing between CML and CTC, the core team collaborated over five years to develop the first feasible plan. The name ImaginOn was agreed to and ready when the facility was dedicated in 2005.

The collaboration that led to ImaginOn demonstrated a structured process for how two different organizations can come together to develop a common space for joint-use. Research showed that representatives of the library and the theater collaborated early during design and development to plan, market and build the shared-use facility. They continued to manage operations with the sharing of knowledge and communications required to operate and sustain the joint use of the facility. Although brand-building involves the whole life of a brand, naming is an essential part of those critical first, design steps that an organization takes in the public world. ImaginOn seems to have been an exceptional type of joint-use facility where two diverse organizations shared a name and vision through almost 15 years of operation.

Future efforts to establish joint-use facilities in organizations, businesses and libraries may benefit from ImaginOn's documented use of KM with sharing knowledge during design and development and a collaborative process for making decisions. The primary issues matrix demonstrates the value of knowledge sharing and KM to resolve concerns and lead to beneficial results. The collaboration process and cognitive model provide recommended procedures and examples for completing design and early development of a successful shared facility.

Results of Phase One might best be summarized as the first part of the "story" of ImaginOn. The product of the labors of the core planning team was the development of a mission statement, a vision for partnership and a set of core values. ImaginOn's vision focused on family and the goal to be a destination of choice for families in the Charlotte-Mecklenburg area in their spare time. In Phase Two, ImaginOn's story was found to be continuing over 15 years to sustain the vision with children's library and theater staff, volunteers and administrators working together to serve children and parents.

\subsection{Phase two: sustainability of collaboration and innovation}

After validating collaboration in the cognitive modes and issues resolutions models in Phase One, we then gathered primary data and selected KM models of process and IC to analyze joint-use operations planning in search of examples of collaborative innovations that helped to sustain the facility. A foundation for KM model analysis was found in Morten Hansen's work (2009):

- evaluate opportunity;

- analyze if barriers to collaboration exist in organization; and

- tailor solutions using collaboration enablers.

Thus, the research goal in Phase Two was to verify management efforts to use KM practices for sustaining collaborative innovation. Using model analysis methodologies, five models of KM practices were applied: 
1. SECI (tacit and explicit knowledge development);

2. IC model analysis (intangible assets);

3. Knowledge sharing (post-project reviews);

4. Collaboration model barriers (matrix for tangible asset issues); and

5. Cognitive modes of collaboration model.

4.2.1 Qualitative data analysis. Primary qualitative data was collected during Phase Two starting with a field study in 2020 at the ImaginOn joint-use facility providing data from observations, interviewing staff face-to-face and touring the multiple open spaces, rooms and labs. Guided by the Administrative Support Supervisor, the field study was thorough and included questions about KM applications and collaborative operations and resources. Examples of innovations over 15 years were visible in building and architecture changes, as well as in joint library and theater operations, art projects, displays and event examples described by staff and volunteers.

In addition, semi-structured interview questionnaires were distributed in email to staff and directors to provide primary data on: collaboration tools, knowledge collection practices, meetings to share reports, post-project reviews and personal experiences or stories that enhanced collaborations. The data collected provided evidence of KM models for knowledge sharing and organizational learning in use at ImaginOn without formal KM business plans. A follow-up, focus interview (face-to-face using WebEx), verified the Planning and Partnerships Coordinator's administrative efforts to have structured use of knowledge sharing, to grow the IC of people/staff (Liebowitz, 2012), and to operationalize collaboration with scheduled events across the joint-use organizations. However, the coordinator was not trained in KM or familiar with all the terminology. Nevertheless, the jointuse staff's collaborative behavior when finding solutions in post-project reviews and making strategic plans in regularly scheduled shared programming meetings demonstrated informal KM and KM practices.

In the interview, the Planning and Partnerships Coordinator confirmed how ImaginOn operationalized collaboration, applied tacit knowledge sharing and increased the IC of staff and volunteers. The coordinator gave examples of resulting innovations, such as The Kindness Project and how library-based "story walks" were created by librarians as new marketing media for the theater's films, musical, performances and plays based on children's and popular literature. So although the words "KM" are not used by staff from either the Children's Theater or the Library, KM activities occur and are part of policies and procedures, which also contribute to innovation. The administrators and staff interviewed and surveyed testified to changes and innovation based on collaboration and structured use of knowledge sharing though KM terms were not used. Evidence specifically of tacit knowledge sharing practices that formed KM bridges for collaboration activities and innovations are summarized in the proposed integrated framework based on the results of data and model analysis.

We researched ImaginOn processes to track any evidence of the SECI model (Nonaka and Takeuchi, 1995) and sharing of tacit knowledge. Identifying the beginning of the cycle (socialization) provided analysis of tacit and explicit KM at ImaginOn. Using tacit knowledge is considered an important aspect of innovation development and all explicit knowledge results.

Additional model analysis used the navigator for IC analysis (intangible assets). Information about post-project reviews was collected to analyze knowledge sharing practices. Finally, as applied in Phase One, both the collaboration model or matrix for analysis of tangible asset issues, and the cognitive modes model for collaboration were used in Phase Two. 
4.2.2 Data collection. Qualitative data was collected during a field study at the ImaginOn facility in Charlotte, NC, and from semi-structured interviews distributed as a questionnaire. Records of observations of library patrons (parents, children and teens), staff interviews and a guided tour of the library, labs and theater area were documented as primary data. The Administrative Support Supervisor led the guided tour and answered questions about KM applications, collaboration tools and resources and innovations; also, staff and volunteers helped to answer questions about the operations. Examples of innovations that were highlighted included statues, props and stage decorations, remodeling and architecture changes in the building.

The field research revealed that the maintaining of "maker space" labs and computer resources for young children requires staff with knowledge skills in information systems. Academic curriculum and professional industry analysis have shown for many years the importance of aligning IS with business goals (Lee et al., 1995). Technology changes supported systems managers in the library at ImaginOn working with youth librarians and drama teachers to meet the needs and user growth of ImaginOn. For example, an intern in one lab demonstrated gaming and story making tools.

Following the field study, semi-structured interview questions were prepared for administrators inspired by research on collaboration by Wendy Duff, Jennifer Carter, Joan Cherry, Heather MacNeil and Lynne Howarth (Duff et al., 2013). Due to library closures in 2020 during the Covid-19 pandemic, instead of in-person interviews as planned, questionnaires were sent by email to staff and partnership administrators at ImaginOn. The questions provide explanations of KM terms with general synonyms to encourage open responses and personal interpretations. The questionnaire was limited in scope because it was designed to focus on potential verification of the use of tacit knowledge and collaboration. The semi-structured questions as listed in Appendix 4 covered the topics of collaboration tools, knowledge collection practices, scheduled meetings to share knowledge, post-project review processes and personal experiences or stories that enhanced data with tacit knowledge about collaboration (Wildemuth, 2017). Qualitative data analysis of the questionnaires involved sorting topics and issues to support KM and collaboration models.

KM knowledge sharing model analysis was used in designing the semi-structured interview questionnaires for collecting data on innovation and collaboration:

- evaluate opportunity;

- analyze if barriers to collaboration exist in organization; and

- tailor solutions using collaboration enablers (Hansen, 2009).

[Note: Electronic distribution of the questionnaires was used instead of in-person interviews because of the Covid-19 closure of offices and libraries. About $30 \%$ of the questionnaires $(n=10)$ were completed and returned by email.] The responses provided primary data about communication tools, collaboration, post-project reviews and KM practices. The data provided evidence of KM and SECI models in use although there are no explicit business plans at ImaginOn to apply KM.

Answers to the first question showed that there were few dedicated communication tools to support collaboration. As one respondent noted, there were barriers based on the absence of tools; for example, without collaborative tools they could not share collective calendars when scheduling joint meetings. Nevertheless, the pattern of meetings supported regular communications, after action reviews and collaboration across the joint-use staffs.

4.2.3 Model analysis. Qualitative data about critical issues and resolutions indicated the occurrence of collaboration. In Phase Two the collected primary data or text was sorted and analyzed based on: assumptions, responses and end results. This qualitative data analysis 
methodology as developed by Miles and Huberman (1994) provided a structured and replicable research approach using an iterative process to document models.

4.2.3.1 Socialization, externalization, combination and internalization model analysis. A significant model analysis applied to Phase Two used the SECl model, in which the four stages of SECI illustrate a cyclical evolution of knowledge from tacit to explicit (Roughen and Swain, 2019). The SECI model (Nonaka and Takeuchi, 1995) was used to evaluate tacit and explicit knowledge applications during on-going joint-use facility operations. Both the original core team designing spaces and branding ImaginOn and the collaborative planning teams over 15 years repeatedly went through the four stages of SECI. The core team was described in one questionnaire response as "forming a new, hybrid organization/ work culture" that involved working directly on the facility with architects, construction crews and public artists. Plus, the core team's hybrid work involved participating in fundraising, developing goals and objectives and organizing the staffing plan to carry out operations. The SECI model was used in data analytics as shown in Figure 3.

The knowledge conversions are defined as:

- Tacit to tacit - meaning is transmitted by observation, experience and practice; knowledge is learned and remains as a form of know-how or skill (socialization).

- Tacit to explicit - "Converting tacit knowledge into explicit means finding a way to express the inexpressible" (Stewart, 1997). For example, moving from tacit to explicit involves expressing the values of the brand in some tangible fashion (externalization).

- Explicit to explicit - meaning is transmitted through recombination of existing knowledge (combination).

- Explicit to tacit - customer or user reframes or interprets knowhow (learning by doing) in such a way that others can understand and learn. "A person's unique tacit knowledge can be applied in creative ways to broaden, extend or reframe a specific idea. Tacit knowledge does not become part of a person's knowledge base until it is articulated and internalized (internalization)" (Smith, 2001, p. 316).

Furthermore, we were able to use SECI model analysis on Phase Two primary data to show knowledge evolution by both the early core team and in later collaboration by partners at ImaginOn as illustrated in Table 5. SECI model analysis to define phases was applied to the primary data from the field trip and from the semi-structured interview questionnaires. Table 5 shows three cycles of the SECI model at ImaginOn based on core team, customer and community activities.

Figure 3 SECI model: tacit and explicit conversions

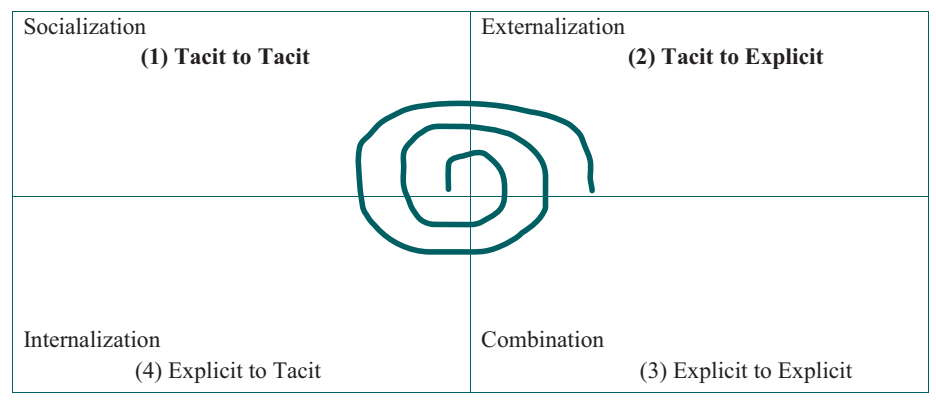

Source: Adapted from Nonaka and Takeuchi (1995) 
Table 5 SECI Cycles at ImaginOn (2006-2020)

\begin{tabular}{|c|c|c|c|}
\hline Phases & Cycle one (core team) & Cycle two (customers) & Cycle three (community) \\
\hline $\begin{array}{l}\text { Tacit to tacit } \\
\text { (socialization) }\end{array}$ & $\begin{array}{l}\text { A "beautiful partnership" } \\
\text { with tacit library and tacit } \\
\text { theatre knowledge }\end{array}$ & $\begin{array}{l}\text { Both library and theatre } \\
\text { perspectives on joint-use } \\
\text { experiences: "where stories come } \\
\text { to life" }\end{array}$ & $\begin{array}{l}\text { Share meanings for the "i" in "kind" } \\
\text { (staff, children, caregivers/parents } \\
\text { and community supporters) }\end{array}$ \\
\hline $\begin{array}{l}\text { Tacit to explicit } \\
\text { (externalization) }\end{array}$ & $\begin{array}{l}\text { Document explicit goals } \\
\text { and objectives for joint-use } \\
\text { facility incorporating tacit } \\
\text { ideas }\end{array}$ & $\begin{array}{l}\text { Establish multiple focus groups of } \\
\text { caregivers and children (the } \\
\text { customers) to understand the types } \\
\text { of experiences }\end{array}$ & $\begin{array}{l}\text { Theatre launches "The Kindness } \\
\text { Project" to commission and develop } \\
\text { original plays that demonstrate acts } \\
\text { of kindness to children }\end{array}$ \\
\hline $\begin{array}{l}\text { Explicit to explicit } \\
\text { (combination) }\end{array}$ & $\begin{array}{l}\text { Combine defined roles from } \\
\text { each institution into "brand } \\
\text { statement" (Doucett, 2008) }\end{array}$ & $\begin{array}{l}\text { Document ideas in Story Lab: } \\
\text { magnetic wall to post ideas, puppet } \\
\text { area to try a story, "Story Jar" } \\
\text { contributions and scavenger hunts, } \\
\text { shareware computers to interact }\end{array}$ & $\begin{array}{l}\text { Community participants can attend } \\
\text { plays and can post to social media } \\
\text { personal story, photo or video } \\
\text { examples of acts and ideas that } \\
\text { promote kindness }\end{array}$ \\
\hline $\begin{array}{l}\text { Explicit to tacit } \\
\text { (internalization) }\end{array}$ & $\begin{array}{l}\text { Propose "ImaginOn" as } \\
\text { name and brand to partner } \\
\text { teams, stakeholders and } \\
\text { community }\end{array}$ & $\begin{array}{l}\text { Use Studio i for projects: build real } \\
\text { and virtual objects; create animated } \\
\text { or stop-action videos; record music }\end{array}$ & $\begin{array}{l}\text { Library and theatre staff promote: } \\
\text { Be the "i" in "Kind" with displays, } \\
\text { carts, Children's Librarian's books } \\
\text { and materials in display }\end{array}$ \\
\hline
\end{tabular}

Each institution in the partnership defined its role and grew in the lives of patrons in terms that were meaningful and part of the brand and mission (Doucett, 2008). Establishing the name "ImaginOn" is the first cycle example. The second cycle covers how children and teens began using Story Lab tools and Studio i (imagination) spaces to tell stories as from literature and for creation of dramas. A community effort to promote service, The Kindness Project, grew out of staff's and patron's ideas in the third cycle.

4.2.3.2 Intellectual capital analysis. At ImaginOn, the structured use of knowledge sharing in facilities, labs and community projects, promoted the growth and nurturing of IC among theater and children's library staff. IC comes from people or human resources (Liebowitz, 2012), and in the joint-use library/theater facility it grew to include social, educational, cultural and creative activities. As shown in Phase One, at first there was IC from the naming and branding collaboration to launch ImaginOn, but IC had to grow to sustain the joint-use facility as Phase Two research documents.

Applying the Skandia Navigator model (Wall et al., 2004) for IC data analysis, we identified how collaboration promoted innovation at ImaginOn. Examples of each of the key IC dimensions from data collected during the field study's staff interviews and tour of ImaginOn (and from excerpts from the survey questionnaires) show continued growth of IC for people resources and users, supporting innovation, as summarized in the following Table 6 .

IC is an important part of research and business planning in the 21st century, but it remains hard for organizations and companies to measure the cost of implementing KM and any resulting intellectual liabilities on profit-loss balance sheets (Dalkir, 2017, p. 372). The goals to improve knowledge sharing, reuse, learning, collaboration and innovation to ensure measurable growth were supported by the Planning and Partnership Coordinator during a final, focus interview to share findings. The coordinator focuses on the business of the publicly funded library and the profit-seeking theater, and serves on the ImaginOn Board with two library and two theater representatives. Their collaboration seemed to nurture IC among all the ImaginOn staff.

In non-library businesses, there are examples of structured use of IC, such as Buckman Labs in Memphis, TN, where the speed to develop new products increased 30\%-35\% (Angus, 2003). At ImaginOn the evidence of the four dimensions of IC were discovered 
Table 6 IC dimensions: Sorting data

Intellectual capital

No. dimension Examples

1

Financial focus (monetary)

Joe and Joan Martin Center; revenue from drama productions; support summer camps

2 Customer focus (value of customer capital) Provide space with Wi-Fi links for adults who wait during children's drama workshops. Display and support "Flag of Hope" with handprints from NC diverse communities (2011) created by Edwin Gil, local Charlotte artist to bridge cultures and groups. [From semi-structured interview questionnaire: after Gil retirement, "we hosted another kid-based community art projects"]

3 Process focus (effective application of technology)

Provide computers, maker space and software labs to support: interactive sharing of story ideas, developing scripts in "story lab," creating videos and animation in a studio and studying computer programming

$4 \quad$ Renewal and development In 2010, converted little used gift shop into vending (the innovative capabilities of organization) area with "store" to sell donated books (small profit innovation)

Adapt "The Round" meeting and presentation room for collaboration planning with staff and stakeholders (parents, volunteers, teens) [Changed "The Balcony" into "Flag of Hope" community focus (described above) = semistructured interview data. [R]enamed the Balcony "Corner of Diversity" and since 2012, we have had several iterations of Edwin's "Faces of Diversity" and "Painting4Diversity" displays. Continued facility changes and innovations; see "Story" - tacit knowledge]

during the field study and in the semi-structured interview questionnaires as part of customer focus and innovative renewal and development (Table 6).

4.2.3.3 Knowledge sharing model analysis. After action reviews or project post-mortems enhance knowledge sharing by allowing reflective considerations so that team members can share tacit knowledge (Dalkir, 2017). Resulting lessons learned from the post-project reviews can support innovation. At ImaginOn the level of detail from an after action or postproject review depends on the type of event. Shared programs are from library and theatre organizations as listed on a bi-monthly agenda from 2019: Super Saturdays, Theatre 360, Theatre Shelving, Augmented Realities, Sensory Path, The Kindness Project, Story Walk, Story Jar (scavenger hunt), Page Stage and Visiting Author talks. A lot of details can be collected, for example, from "Super Saturdays," which are when an outside presenter or performer is contracted to provide free, family friendly entertainment, and they are independent of theatre or library programming. Tangible data on attendance is retained, and if there are problems, notes about any issues are recorded so that the next time the performer comes, the staff can be proactive and explicitly document the lessons learned from the shared knowledge. As an example, a performer using paint or soap bubbles might go outside a designated stage area and require that future maintenance staff be on-hand to clean up after the show. For larger scale events, such as a well-known author speaking, warrant an "Event Report," which includes time-line, kudos/praise, complaints, set-up details and any pictures. If there is no debriefing, the Planning and Partnership Coordinator obtains information for a report via structured questions in emails, documents reviews and retains these records in learning history files (Roth and Kleiner, 1998). In addition to post- 
project reviews, "focus groups" were held at ImaginOn, during early development to encourage tacit knowledge sharing among the users, the children and their caregivers, who described the types of experiences they want at the joint-use facility. Thus, knowledge sharing may be an important part of operations in a learning organization.

Overall, the KM of operational processes at ImaginOn supports knowledge sharing. Processes cover tangible assets and intangible assets, as well as the sharing of tacit knowledge. The learning histories that promote organizational memory (Roth and Kleiner, 1998) also seem to lead to process/procedural changes and innovations at ImaginOn. Knowledge sharing within joint-use facilities can become systematic because of regular post-project reviews and lessons-learned discussions by the partner organizations meeting together. Although ImaginOn did not use a "knowledge journalist" (Dalkir, 2017) to record post-project review findings, the open, knowledge sharing by staff from both organizations was evident in notes from the bi-monthly "Shared Programming" meetings. Plus, it is the responsibility of the Planning and Partnerships Coordinator to bring together library and theatre staff for planning, team-building and social events, which promote collaborative innovations; thus, the Coordinator acts as a knowledge journalist recording meeting notes and post-project reports in learning histories.

4.2.3.4 Collaboration model barriers analysis. Issues related to tangible assets could become barriers to collaboration as analytics might show. Iterative qualitative data analysis of information collected in Phase Two distilled examples of potential barriers to collaborating into four significant barriers stemming from tangible asset issues. Table 7 illustrates in a matrix model the four most significant asset-based issues collected in Phase Two that needed to be resolved to support collaboration. However, as the end results indicate, there are no final operational resolutions mainly due to different policies and separate budgets for the partner organizations, Children's Library and Children's Theatre. However, both Response and End Results columns document collaborations and innovations.

The issues matrix to evaluate collaboration (Table 7) suggested to researchers that model analysis of the knowledge-sharing process during operations might illustrate uses of KM practices in business processes.

Table 7 Matrix of operational collaboration issues at ImaginOn

\begin{tabular}{|c|c|c|c|}
\hline Issue & Assumption & Responses & End results \\
\hline $\begin{array}{l}\text { Use of collaboration support } \\
\text { tools }\end{array}$ & $\begin{array}{l}\text { Both CML and CTC teams can } \\
\text { share calendars to schedule } \\
\text { meetings }\end{array}$ & $\begin{array}{l}\text { Each organization uses its own } \\
\text { Microsoft Office suite; } \\
\text { scheduling meetings together } \\
\text { can be a "nightmare" }\end{array}$ & $\begin{array}{l}\text { Extra time required by staff and } \\
\text { administrative assistants to } \\
\text { schedule shared meetings }\end{array}$ \\
\hline $\begin{array}{l}\text { Social media to promote } \\
\text { ImaginOn exhibits, plays, } \\
\text { speakers and events }\end{array}$ & $\begin{array}{l}\text { ImaginOn has its own Facebook } \\
\text { and website (separate from } \\
\text { CML or CTC) so content can } \\
\text { promote library and theatre } \\
\text { partners equally }\end{array}$ & $\begin{array}{l}\text { The Theatre has its own "social } \\
\text { media specialist" and library } \\
\text { has a separate team for } \\
\text { "marketing and } \\
\text { communications" }\end{array}$ & $\begin{array}{l}\text { One shared staff person works } \\
\text { with both partners to oversee } \\
\text { ImaginOn Facebook and promote } \\
\text { content "equitably" }\end{array}$ \\
\hline $\begin{array}{l}\text { Revenue from programs and } \\
\text { events at ImaginOn }\end{array}$ & $\begin{array}{l}\text { Tangible assets or money } \\
\text { collected (room rentals, } \\
\text { vending machines and sales of } \\
\text { tote bags) is shared to avoid } \\
\text { "kerfuffles" }\end{array}$ & $\begin{array}{l}\text { Not shared; set specific line } \\
\text { items in CML and CTC separate } \\
\text { budgets for non-profit funds; not } \\
\text { prepared for profits from } \\
\text { speakers or plays }\end{array}$ & $\begin{array}{l}\text { ImaginOn is not incorporated, so } \\
\text { donations and collections must be } \\
\text { earmarked to CML or to CTC } \\
\text { separately }\end{array}$ \\
\hline $\begin{array}{l}\text { Designate space to promote } \\
\text { diversity }\end{array}$ & $\begin{array}{l}\text { Original open space nicknamed } \\
\text { "The Balcony" showed traveling } \\
\text { exhibit, "Changing Places" } \\
\text { about culture in the south, from } \\
2011-2012 \text {, could continue to } \\
\text { support diversity art }\end{array}$ & $\begin{array}{l}\text { ImaginOn partnered with local } \\
\text { artist, Edwin Gil to display "Flag } \\
\text { of Hope" and other art pieces in } \\
\text { space until retirement in } 2017\end{array}$ & $\begin{array}{l}\text { Unofficially CML and CTC } \\
\text { renamed space as "Corner of } \\
\text { Diversity" and shared staff seeks } \\
\text { art about diversity, such as kid- } \\
\text { based community art and a } \\
\text { children's book exhibit from China. } \\
\text { Ongoing }\end{array}$ \\
\hline
\end{tabular}


Tracking tangible assets is of particular importance when analyzing business processes. For the ImaginOn case study, such assets were defined in Phase Two and documented in the questionnaire as tangible business accounts (income from used book store or gift shop) and quantitative data (attendees at theater shows, books and media checked out). Questionnaire responses also showed that program/theater attendance data has been used to define the types of spaces needed, to determine how many spaces would be occupied at one time, and which partner organization would have priority access and when. The use of space was documented in an organization operating agreement. KM includes tracking and accessing data about tangible assets during operational processes and making decisions or innovative solutions using the data.

4.2.3.5 Cognitive modes of collaboration analysis. The semi-structured questionnaire responses provided a strong example of cognitive modes and collaboration when describing the resolution of a problem when a performer used soap bubbles beyond the designated stage area. The "story" of the event and later policy changes were described by the Planning and Partnerships Coordinator providing details from a bi-monthly shared programming meeting of library and theater staff. Collaboration by theatre, library and maintenance staff led to operation innovations when planning events and new policies requiring additional maintenance staff to clean up after the show. The cognitive modes are illustrated in Table 8.

4.2.4 Results of knowledge management, collaboration and innovation analysis. Results of Phase Two are part of the ongoing "story" of ImaginOn. Interviews with staff and volunteers during the tour of the facility, questionnaire responses and a final focus interview provided examples of operationalized collaboration, applications of tacit knowledge (with SECI transformation) and growth of $\mathrm{IC}$ in the resources provided by staff and volunteers (Liebowitz, 2012). The year 2020 marked the 15th anniversary of ImaginOn, where children have created stories for successful events based on creative innovations from library and theater staff.

An example of successful collaborative planning knowledge sharing by staff and both children and parents was "The Kindness Project" that is still ongoing. Starting as a community service effort, The Kindness Project was an innovation launched by the theater team that also applied ideas from the library's staff, volunteers and patrons. Participants posted examples of acts of kindness on a bulletin board and in social media chats (with the

Table 8 Collaborative process and cognitive modes in after action review

\begin{tabular}{|c|c|c|c|}
\hline $\begin{array}{l}\text { Modes } \\
\text { and submodes }\end{array}$ & Goals & Products & Knowledge sharing \\
\hline Discussion & Resolve cleaning problem & $\begin{array}{l}\text { Collect details about bubble } \\
\text { performance }\end{array}$ & $\begin{array}{l}\text { Dialog: during bi-monthly shared } \\
\text { programming meeting }\end{array}$ \\
\hline Conflict resolution & & Respond to maintenance staff & $\begin{array}{l}\text { Safety later and maintaining rooms } \\
\text { discussed }\end{array}$ \\
\hline Brainstorm & & Policy ideas & \\
\hline Presentation & New Policy on clean up & $\begin{array}{l}\text { Draft of policy for bubbles (regular } \\
\text { performer) and paint, etc. }\end{array}$ & $\begin{array}{l}\text { Inform about success of show for } \\
\text { audience } \\
\text { Teach about cleaning requirements } \\
\text { Listen, learn, question and evaluate }\end{array}$ \\
\hline Summary & $\begin{array}{l}\text { Represent theatre and } \\
\text { library }\end{array}$ & & \\
\hline Demo & Outline solution & & \\
\hline Delegation & $\begin{array}{l}\text { Assign policy and plans for } \\
\text { future }\end{array}$ & $\begin{array}{l}\text { Planning and Partnership } \\
\text { Coordinator writes policy for after } \\
\text { event cleaning }\end{array}$ & $\begin{array}{l}\text { Tell the performer and maintenance } \\
\text { staff } \\
\text { Listen and evaluate (follow-up after } \\
\text { next bubble show) }\end{array}$ \\
\hline
\end{tabular}


2020 pandemic patron visits in person dropped, but online sharing grew and theatrical shows evolved into film productions). The Children's Library provided a location and tools for collecting kindness information, and the Children's Theater of Charlotte's teachers and student groups developed performances to illustrate the acts. The goal was for ImaginOn's children, parents and teenage patrons and for the local community to view theatrical film productions and see kindness as an activity performed by real people. ImaginOn continued to be a destination location for the community both in-person and virtually in 2020.

Data results from Phase Two qualitative analysis provided evidence of $\mathrm{KM}$ in use at ImaginOn without formal, defined KM business or project planners purposefully applying "KM." Also, the evidence of practices that form KM bridges for the partner institutions in the joint-use facility illustrated innovative collaborations. The research using KM model analysis suggested the possibility of an integrated framework that applies three key KM elements:

1. tacit and explicit knowledge;

2. the creation, sharing and implementation of processes; and

3. enablers from technology, leadership, culture and strategy (Dei, 2019).

Applications of the navigator model also demonstrated the development and use of IC assets during innovative planning. Our research results led to the creation of a framework for KM practices in joint-use facilities.

\section{Conclusion: a framework}

Our primary research question for this study asked how KM might sustain innovation when organizations from different cultures collaborate to plan a joint-use facility? Research covered two phases and described innovations, sustained planning and creative collaborations based on knowledge sharing that applied tacit knowledge, the growth of IC as part of the human resources of both organizations and operational collaboration by library and theater staff. An integrated framework was derived from the research using model analytics of KM practices. ImaginOn as a case study provided an example of sustainability of a business and of innovative collaboration. The model-based framework may be used to guide other joint-use groups to share knowledge, increase IC and collaborate during strategic and operational planning. The framework integrated KM models and was enhanced by two models that enable collaboration: issues matrix analysis and cognitive modes.

ImaginOn was designed and developed as a place with a joint-identity, where two distinct institutions could be co-located and thrive in a hybrid, joint-use facility. Despite different identities, cultures and business goals, as ImaginOn they became one entity. In their jointuse facility, librarians and theater producers inspire the interest and support of the public through collaborative, innovative programs. Furthermore, its original identity has remained the same despite changes in management, government, the economy and the operating agreements that govern it. The continued application of KM practices and collaboration has led to a stable joint-use facility that is highly adaptable, flexible and reconfigurable with daily accommodations for new exhibits, events and programs. As one author on joint-use facilities has noted:

[...] [b]efore the would-be partners in a joint-use library decide what automation system to use, who pays the electricity bill, or how broken furniture is replaced, they must arrive at a common vision for the new library (Dornseif, 2001)

This KM study of ImaginOn provides an example of how the first planning steps of design and developing a vision of a joint-use facility for different organizations can lead to success and sustainable operations. 
ImaginOn continued to be successful and emerged from the 2008 recession as a valued, community institution. The longevity, stability and acceptance of the ImaginOn mission to support children's story-telling demonstrated how a joint-use facility really can be an "experience." The KM and collaboration in ImaginOn was found by our research to demonstrate applications of tacit knowledge (with SECI transformation), growth of IC and operationalized collaboration. As noted earlier, explicit information and policies without tacit insight can lose meaningfulness (Alwis and Hartmann, 2008). The innovations at ImaginOn demonstrated new ideas for operations and significant improvements in art-based services to children through cutting edge exhibits, live performances and interactive features that related to books and reading. Gathering results of the model-based analyses of qualitative data, an integrated framework for KM in a joint-use facility emerged. The framework illustrated in Figure 4 may help others plan successful collaborative operations that build on $\mathrm{KM}$. For sustaining a business and managing with innovation, there are examples from ImaginOn's creative staff, volunteers, children and parents and an involved community.

\subsection{Integrated framework as a knowledge management tool}

Recent reviews of organizations that manage their knowledge suggests it is important to understand what knowledge is and what management of it can mean to operations. KM processes, practices and enablers make up the framework and can contribute to guidelines. An integrated framework built from a collection of successful implementations also can be the basis for a future, stronger theoretical foundation in KM (Dei, 2019).

A framework can be defined as a system of people, processes, governance and technology (Dei, 2019). Furthermore, it is through the application of management functions in knowledge acquisition processes that a framework is expressed (Mostert and Snyman, 2007). For example, the SECI model for tacit-explicit knowledge conversion from Nonaka and Takeuchi (1995) can be considered a framework and demonstrated to be applied by an organization. Thus, the question emerging from this ImaginOn case study is whether or not "KM" must be explicitly labeled as KM to provide a functioning framework of practices that helps an organization sustain innovation and collaboration for a competitive market advantage? The framework in Figure 4 defines how joint-use partners in libraries, the arts and government can manage knowledge successfully through $\mathrm{KM}$ practices without calling it "KM." Furthermore, the framework might be used as an organizing principle to implement $\mathrm{KM}$ in hybrid and information-focused businesses and organizations (Dalkir, 2017). Eventually formal or designated KM departments and knowledge workers could use the

Figure 4 Model-based framework for collaboration through the application of KM practices

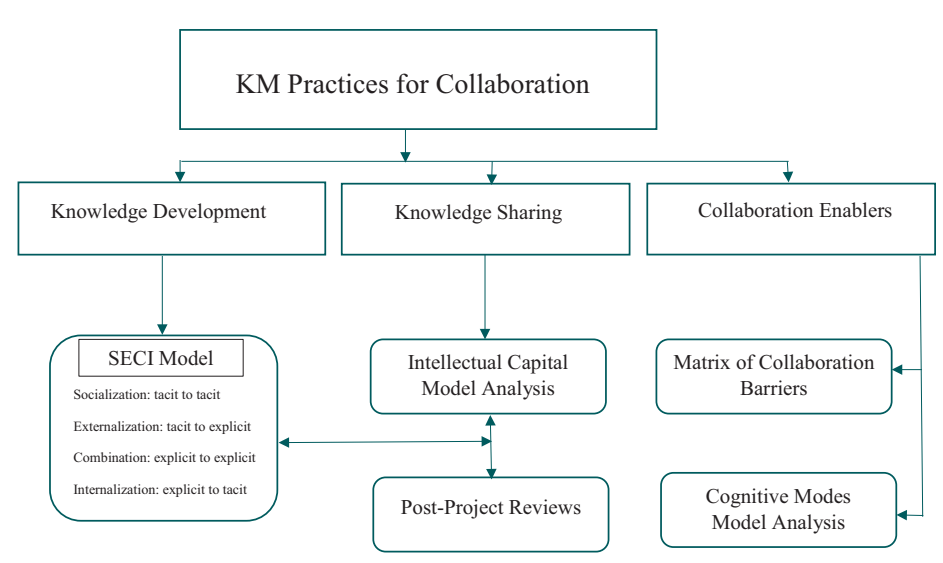


framework to improve decision-making, enhance collaboration and develop new models and processes.

\subsection{Integrated framework for joint-use facility application}

Evidence of the knowledge sharing practices that formed KM bridges for collaborative activities and innovations are summarized in the framework built from this ImaginOn case study. Using model analysis applied to qualitative data, a "KM Framework for Collaboration in Joint-Use Facilities" was designed to integrate:

- development of tacit and explicit knowledge from the SECI model;

- IC model analysis of intangible assets;

- knowledge sharing practices from post-project reviews;

- a matrix model of collaboration barriers for tangible asset issues; and

- the enabling of collaboration using cognitive modes.

Overall, the framework can assist joint-use and collaborative organizations to implement KM practices before formal departments or directors of KM are defined. Each aspect of the framework impacts organizational performance. This research has shown how effective collaboration can be a key to sustained innovation. Enablers for collaboration are included in the framework.

The "model-based framework for collaboration through the application of km practices" is illustrated in Figure 4, and is based on a design derived from Dei's (2019) framework for KM practices.

The knowledge development column on the left demonstrates utilization of the SECI model, which originally demonstrated how companies in Japan achieved creativity and innovation. The creation or development of knowledge by any project or collaborative organization starts with "socialization" of tacit knowledge. The internalized knowledge that may be difficult to articulate or simply has not been shared with anyone is tacit. Thus, the beginning of knowledge creation starts with one person giving others imbedded "new" knowledge, which remains tacit at first. Next, the tacit knowledge is made external or explicit during the "externalization" mode. In the third phase of the SECl cycle, awareness of the knowledge expands and transformation occurs as explicit knowledge changes into different and additional explicit knowledge during the "combination" mode. In the fourth phase of the cycle, new tacit knowledge is created from explicit knowledge and thus "internalization" occurs. As a KM practice, adoption of SECl strengthens an organization's use of employees' tacit knowledge that can be lost or forgotten otherwise and supports creativity and innovation.

The knowledge sharing column in the center of the framework shows the application of both IC model analysis and post-project reviews as key KM practices. Intellectual capital at the core of the navigator model has four dimensions, which are human focused:

1. Financial focus (monetary);

2. Customer focus (value of customer capital, both financial and non-financial);

3. Process focus (effective application of technology); and

4. Renewal and development (the innovative capabilities of organization).

Continued use of IC as shown in the model supports continued innovation. After-action post-mortems or post-project reviews seem to enhance knowledge sharing by allowing reflection and the sharing of tacit knowledge. Applying lessons learned from the postproject reviews of collaborative work may lead also to new innovations. 
Two KM practices that enable collaboration are illustrated in the right column: issues matrix analysis and cognitive modes of collaboration. Less prevalent in lists of KM practices, these two model-based analytical tools can assist partners in a joint-use facility or other combined "hybrid" organization to sustain collaboration. The issues matrix model can be used to identify tangible asset issues that could become barriers to collaboration. That is, the model enables teams to define the issues that might be significant barriers to knowledge sharing and collaboration. Sorting issues into a matrix in terms of assumptions, responses and end results can demonstrate to a team that problems can be resolved and innovation applied. Thus, the matrix can be a tool used to enable collaboration.

Furthermore, knowing that a group's cognitive modes occur in three basic collaborative thought-processing sequences can help members determine where they are and what to do next to collaborate successfully. The modes are:

- Discussion or brainstorming to externalize information and resolve conflicts;

- Presentation, summary or demonstration of prototypes to introduce information to team members; and

- Delegation and decision-making to assign appropriate tasks or evaluations (acting on knowledge).

This framework of KM practices is based on the ImaginOn case study covering over 15 years of sustained knowledge sharing and collaboration planning for a hybrid, joint-use facility. The framework provides models that can be applied to any business that merges and reorganizes two or more groups. If the goal is to support collaborative, learning processes, then the framework integrates KM to meet that goal by developing innovation and succeeding in a market of community-based organizations.

\section{Looking to the future}

Future KM measurement tools may help track innovations and connect them to specific KM processes and practices. Just as companies make products, libraries and children's theaters produce learning, which through KM can increase the number of lessons and impact on patrons and communities more quickly. Our research demonstrated collaborative innovations based on KM practices and outlined a framework for collaborative planning based on model analytics. The framework could be considered an integrated, generalizable KM framework for collaboration; however, more case studies need to be analyzed. In addition, creative energy as was expressed by library and theatre staff at ImaginOn might be understood better and sustained by KM practices based on additional models and analysis.

Our research began with the question: how might innovation be sustained by KM when organizations from different cultures are merged? The sustaining of innovation in planning has been shown in this case study to be supported by KM practices even when the term "KM" was not part of the vocabulary of the Planning and Partnerships Coordinator or of library and theater staff and volunteers. Data collected on informal KM in a joint-use facility showed processes that support sharing tacit knowledge, the growth of the IC of people/staff and the application of collaboration when participants across the joint-use organization plan shared events, space use and fund raising.

The story of ImaginOn is a story of sustained knowledge sharing, IC growth and collaboration that might be applied in future planning efforts by merged organizations with different cultures. Whether merging businesses or forming joint-use facilities, applying KM models can support and sustain a learning organization as shown in this study. Future research about different types of institutions might analyze organizational data using additional KM models and introducing new theories of creative knowledge-sharing and innovation. 


\section{References}

Adesina, A. and Ocholla, D. (2019), "The SECl model in knowledge management practices: past, present, and future", South African Journal of Information Studies, Vol. 37 No. 3, p. 34.

Alwis, R. and Hartmann, E. (2008), "The use of tacit knowledge with innovative companies", Journal of Knowledge Management, Vol. 12 No. 1, pp. 122-147.

Angus, J. (2003), KM's Father Figure: Robert Buckman, InfoWorld, March 14.

Baron, M. (2016), Takeaways from a Perfect Library-Theatre Partnership, School Library Journal, avilable at: www.slj.com/?detailStory=takeaways-from-a-perfect-library-theatre-partnership (accessed 24 September 2018).

Bauer, P.T. (2006), "Changing places: personnel issues of a joint use library in transition", Library Trends (Trends), Vol. 54 No. 4, pp. 581-595.

Beckett, R. (2016), "The use of wiki tools in collaborative research and learning", Journal of Technologies in Knowledge Sharing, Vol. 11 No. 4, pp. 13-26.

Block, M. (2007), The Thriving Library: Successful Strategies for Challenging Times, Information Today, Medford, NJ.

Bundy, A. (2008), “Joint use libraries for the future”, APLIS, Vol. 21 No. 3, pp. 135-136.

Bundy, A. and Amey, L. (2006), "Libraries like no others: evaluating the performance and progress of joint use libraries", Library Trends (Trends), Vol. 54 No. 4, pp. 501-518.

Casstevens, S. (2017), "Joint-Use libraries: a living room of learning", Knowledge Quest (November), Vol. 46 No. 2, pp. 62-71, available at: http://nclive. org.ezproxy.nccu.edu/cgi-bin/nclsm?url=http://search. proquest.com.ezproxy.nccu.edu/docview/1960343921?accountid $=12713$

Chen, C., Lin, B., Lin, J.-Y. and Hsiao, Y.-C. (2017), "In search of parents' knowledge for joint venture's innovation", Technology Analysis \& Strategic Management, Vol. 29 No. 2, pp. 190-203.

Chesbrough, H.W. and Crowther, A.K. (2006), "Beyond high-tech: early adopters of open innovation in other industries", R and D Management, Vol. 36 No. 3, pp. 229-236.

Dalkir, K. (2009), "Knowledge management", in Bates, M. and Maack, M. (Eds), Encyclopedia of Library and Information Science, pp. 3129-3138, CRC Press, Boca Raton, FL.

Dalkir, K. (2017), Knowledge Management in Theory and Practice, The MIT Press, Cambridge, MA.

Dalton, P., Elkin, J. and Hannaford, A. (2006), "Joint use libraries as successful strategic alliances", Library Trends ( Trends), Vol. 54 No. 4, pp. 535-548.

Dei, D.-G. (2019), "Developing an integrated framework for knowledge management practices in organisations", South African Journal of Information Studies, Vol. 37 No. 3, p. 20.

Dilevko, J. and Gottlieb, L. (2004), The Evolution of Library and Museum Partnerships: historical Antecedents, Contemporary Manifestations, and Future Directions, Libraries Unlimited, Westport, Conn.

Dornseif, K.A. (2001), "Joint-use libraries: balancing autonomy and cooperation", Resource Sharing \& Information Networks, Vol. 15 No. 1-2, p. 103, available at: http://nclive.org.ezproxy.nccu.edu/cgi-bin/ nclsm?url=http://search. proquest.com.ezproxy.nccu.edu/docview/1960343921 ?accountid=12713

Dorrington, L. (2006), "Health libraries as joint use libraries: serving medical practitioners and students", Library Trends (Trends), Vol. 54 No. 4, pp. 596-606.

Doucett, E. (2008), Creating Your Library Brand: Communicating Your Relevance and Value to Library Patrons, American Library Association, Chicago.

Du Plessis, M. (2007), "The role of knowledge management in innovation", Journal of Knowledge Management, Vol. 11 No. 4, pp. 20-29.

Duff, W., Carter, J., Cherry, J., MacNeill, H. and Howarth, L. (2013), "From coexistence to convergence: studying partnerships and collaboration among libraries, archives, and museums", Information Research: An International Electronic Journal (September), Vol. 18 No. 3, p. 26.

Dunford, H. (2009), "Reference work on joint-use libraries", The Australian Library Journal, Vol. 58 No. 1, pp. 107-108. Review of Joint-Use Libraries: Libraries for the Future by Sarah McNicol, (2008) Oxford: Chandos.

Earl, M. (2001), "Knowledge management strategies: toward a taxonomy", Journal of Management Information Systems, Vol. 18 No. 1, pp. 215-233. 
Edvinsson, L. and Malone, M. (1997), Intellectual Capital: Realizing Your Company's True Value by Finding Its Hidden Brainpower, Harper Business, New York, NY.

Eva, N. and Shea, E. (2018), "An interview with mark aaron polger, editor of marketing libraries journal", Reference \& User Services Quarterly ( Quarterly), Vol. 57 No. 4, pp. 251-253.

Freeman, J. and Katz, R. (1978), "Information marketing", Annual Review of Information Science and Technology, Vol. 13, pp. 37-59.

Future of the Library Task Force (2011a). "Public library funding: comparing Charlotte mecklenburg library and selected library systems (FY 2008-FY 2011)", available at: https://ui.uncc.edu/story/publiclibrary-funding-comparing-charlotte-mecklenburg-library-and-selected-library-systems

Future of the Library Task Force (2011b). "Recommendations from the future of the library task force", available at: www.mecknc.gov/CountyManagersOffice/OMB/CapitalProjects/Documents/FUTURE\% 200F\%20THE\%2OLIBRARY\%20TASK\%20FORCE\%20-\%2OFULL\%2OREPORT\%2OWTIH\%2OAPPENDICES \%20-\%20MARCH\%2021,\%202011.pdf

Gene Norman, O. (1982), "Marketing libraries and information services: an annotated guide to the literature", Reference Services Review, Vol. 10 No. 1, pp. 69-84.

Greenhalgh, T. (2015), "Higher education governance as language games: a Wittgensteinian case study of the breakdown of governance at the London school of economics 2004-2011", Higher Education Quarterly, Vol. 69 No. 2, pp. 193-213.

Hansen, M. (2009), Collaboration: How Leaders Avoid the Traps, Create Unity, and Reap Big Results, Harvard Business School Publishing, Boston, MA.

Hansen, M., Nohria, N. and Tierney, T. (1999), "What's your strategy for managing knowledge?”, Harvard Business Review, Vol. 77 No. 2, pp. 106-116.

Hansson, J. (2006), "Just collaboration or really something else? On joint use libraries and normative institutional change with two examples from Sweden", Library Trends (Trends), Vol. 54 No. 4, pp. 549-568.

Hood, D. and Henderson, K. (2005), "Branding in the United Kingdom public library service", New Library World, Vol. 106 Nos 1/2, 1 January 2005, ISSN: 0307-4803.

Howard, K., Bocarro, J. and Kanters, M. (2013), "Strategies for creating successful joint use agreement: a case study", Journal of Park and Recreation Administration, Vol. 31 No. 1, pp. 98-107.

Hussinki, H., Ritala, P., Vanhala, M. and Kianto, A. (2017), "Intellectual capital, knowledge management practices and firm performance”, Journal of Intellectual Capital, Vol. 18 No. 4, pp. 904-922.

Imhoff, K. (2001), "Public library Joint-Use partnerships: challenges and opportunities", in Miller, W. and Pelen, R. (Eds), Joint-Use Libraries, Haworth Press, Binghampton, New York, NY, (co-published simultaneously in Resource Sharing and Information Networks, 15(12), 17-39; and reprinted 2014).

Katuscakova, M. and Jaseckova, G. (2019), "Diffusion of KM education in LIS schools", Journal of Education for Library and Information Science, Vol. 60 No. 1, pp. 83-100.

Khumalo, S. and Mearns, M. (2019), "SharePoint as enabler for collaboration and efficient knowledge sharing", South African Journal of Information Management, Vol. 21 No. 1, p. 9.

Kilkka, L. (2008), "ImaginOn: security issues in a joint-use children's library/children's theater facility", Library \& Archival Security, Vol. 21 No. 2, pp. 87-113.

Klingenberg, B. and Rothberg, H. (2020), "The status quo of knowledge management and sustainability knowledge", Electronic Journal of Knowledge Management, Vol. 18 No. 2, pp. 136-148.

Kluever, J. and Finley, W. (2012), "Making connections: challenges and benefits of joint use libraries as seen in one community", School Libraries Worldwide, Vol. 18 No. 1, pp. 48-55.

Koontz, C., Gupta, D. and Webber, S. (2006), "Key publications in library marketing: a review", The International Federation of Library Associations and Institutions, Vol. 32 No. 3, pp. 224-231.

Lamott, A. (1994), Bird by Bird: Some Instructions on Writing and Life, Penguin Random House, New York, NY.

Latilla, V.M., Frattini, F., Petruzzelli, A.M. and Berner, M. (2019), "Knowledge management and knowledge transfer in arts and crafts organizations: evidence from an exploratory multiple Case-Study analysis", Journal of Knowledge Management, Vol. 23 No. 7, pp. 1335-1354.

Lawson, T. and Barry, M. (2001), "School community libraries in South Australia - funding and governance: a research report prepared for the joint use libraries committee", available at: www.lga.sa. 
gov.au/webdata/resources/project/School_Community_Libraries_in_South_Australia.pdf (accessed 20 April 2019).

Lawton, J. and Lawton, H. (2009), "Public-Academic library collaboration: a case study of an instructional house and property history research program for the public", The American Archivist ( Archivist, Vol. 72 No. 2, pp. 496-514, available at: https://americanarchivist. org/toc/aarc/72/2

Lee, T. (2007), "Children's theatre of Charlotte joins hands with public library to create ImaginOn: learning center is groundbreaking model. Linking theatre, literature and technology", The Southern Theatre XLVIII, No. Winter 2007, pp. 34-42.

Lee, D., Trauth, E. and Farwell, D. (1995), "Critical skills and knowledge requirements of is professionals: a joint academic/industry investigation”, MIS Quarterly, Vol. 19 No. 3, pp. 313-340.

Lev, B. (2001), Intangibles - Management, Measurement, and Reporting, Brookings Institute Press, Washington, DC.

Liebowitz, J. (2012), Beyond Knowledge Management: What Every Leader Should Know, CRC Press, Boca Raton, FL.

McNicol, S., (Ed.) (2006), "What makes a joint use library a community library?", Library Trends, Vol. 54 No. 4, pp. 519-534.

Marques, J.M.R., La Falce, J.L., Marques, F.M.R., De Muylder, C.F. and Silva, J.T.M. (2019), "The relationship between organizational commitment, knowledge transfer, and knowledge management maturity", Journal of Knowledge Management, Vol. 23 No. 3, pp. 489-607.

Matthews, K. (2008), "The critical success factors for school and community joint use libraries in New Zealand”, APLIS, Vol. 21 No. 1, pp. 13-24.

Matuozzi, R. (2009), "Library public relations: recent articles on marketing and branding in university libraries", Public Services Quarterly, Vol. 5 No. 2, pp. 135-138.

Mazorodze, A.H. and Buckley, S. (2019), "Knowledge management in Knowledge-Intensive organisations: understanding its benefits, processes, infrastructure and barriers", South African Journal of Information Management, Vol. 21 No. 1, p. 6.

Miles, M. and Huberman, A. (1994), Qualitative Data Analysis: An Expanded Sourcebook, Sage Publications, Thousand Oaks, CA.

Mills, A. and Smith, T. (2011), "Knowledge management and organizational performance: a decomposed view", Journal of Knowledge Management, Vol. 15 No. 1, pp. 156-171.

Mostert, J. and Snyman, M. (2007), "Knowledge management framework for the development of an effective knowledge management strategy", South African Journal of Information Management, Vol. 9 No. 2, pp. 35-94.

Musonza, C. and Muchaonyerwa, N. (2019), "Influence of knowledge management practices on public service delivery by municipalities", South African Journal of Information Studies, Vol. 37 No. 3, p. 19.

Nonaka, I. and Takeuchi, H. (1995), The Knowledge Creating Company: How Japanese Companies Create the Dynamics of Innovation, Oxford University Press, New York, NY.

Pellen, R. and Miller, W. (2014), Joint-Use Libraries, Routledge, Taylor and Francis, New York, NY.

Quinlan, N.J. and Tuñón, J. (2004), "Providing reference in a joint-use library", Internet Reference Services Quarterly, Vol. 9 Nos 1/2, pp. 111-128.

Ralph, L. (2010), Knowledge Management and Libraries: An Annotated Bibliography 1997-2009, Edwin Mellen Press, Lewiston, New York, NY.

Ralph, L. (2012), "Using education informatics to improve library services to doctoral students: an embeded approach", International Journal of Doctoral Studies, Vol. 7, pp. 235-244.

Ralph, L. and Ellis, T. (2009), "An investigation of a knowledge management solution for the improvement of reference service", Journal of Information, Information Technology, and Organizations, Vol. 4, p. 38.

Ralph, L. and Tijerino, C. (2009), "Nota bene: knowledge management and library culture", College and Undergraduate Libraries, Vol. 4, pp. 329-337.

Ratna, R., Srivastava, N. and Rana, G. (2020), "Exploration of organizational culture, knowledge management, organizational effectiveness", International Journal of Psychosocial Rehabilitation, Vol. 24 No. 1, pp. 274-291. 
Richmond, E. and Twyford, L. (2012), "The best of both worlds: the first three years of the wangaretta public/technical and further education library, Victoria", APLIS, Vol. 25 No. 3, pp. 111-115.

Ritchie, R., Swami, S. and Weinberg, C. (1999), "A Brand new world for nonprofits", International Journal of Nonprofit and Voluntary Sector Marketing, Vol. 4 No. 1, pp. 26-42.

Robinson, C. (2006), "Working at a Joint-Use library", Journal of Access Services, Vol. 4 Nos 1/2, pp. 75-84.

Rooney-Browne, C. (2007), "Changing the way We look at libraries? An evaluation of east renfrewshire's look at libraries festival", Library Review, Vol. 57 No. 1, pp. 50-66.

Ross, F. and Woodfield, S. (2017), "Mutuality, metaphor and micropolitics in collaborative governance: a joint venture in UK higher education”, Higher Education Quarterly, Vol. 71 No. 1, pp. 33-52.

Roth, G. and Kleiner, A. (1998), "Developing organizational memory through learning histories", Organizational Dynamics, Vol. 27 No. 2, pp. 43-60, and (2000) in The Knowledge Management Yearbook 2000-2001, Cortada J. and Woods, J.(Eds), Woburn, MA: Butterworth-Heinemann.

Roughen, P. (2016), "System branding in three public libraries: live oak public libraries, Charlotte Mecklenberg library, and Richland library", Library Philosophy and Practice, Paper 1442.

Roughen, P. (2012), "Brand building in three public libraries: live oak public libraries Charlotte Mecklenburg library, and Richland county public library", Dissertation, University of South Carolina.

Roughen, P. and Swain, D. (2019), "Building innovative brands: cases of tacit and explicit knowledge conversions in children's libraries", Public Library Quarterly, Vol. 39 No. 6, doi: 10.1080/ 01616846.2019.1702448.

Rubin, R. (2016), Foundations of Library and Information Science, 4th ed, Neal-Schuman (American Library Association), Chicago.

Sabri, M. and Odeh, M. (2019), "The impact of knowledge management on the development of innovative business process architecture modelling: the case of banking in Jordan", International Journal of Technology Management \& Sustainable Development, Vol. 18 No. 2, pp. 197-220.

Sarjeant-Jenkins, R. and Walker, K. (2014), "Working together: joint-use canadian academic and public libraries", Collaborative Librarianship, Vol. 6 No. 1, pp. 5-19.

Schrage, M. (1995), No More Teams! Mastering the Dynamics of Creative Collaboration, Bantam Doubleday Dell, New York, NY.

Sensuse, D., Gandhi, A. and Sucahyo, Y. (2019), "Exploring the soft system methodology in development of knowledge management conceptual model: a Sy[s]tematic literature review", Desidoc Journal of Library \& Information Technology, Vol. 39 No. 5, pp. 259-266.

Setiyani, L. and Ramadhan, A. (2020), "Using knowledge management system: a taxonomy of SME strategies", International Journal of Psychosocial Rehabilitation, Vol. 24 No. 4, pp. 1001-1005.

Sidorow, K. (2012), "Measuring their success: colocated library and community services", Australasian Public Libraries and Information Services (March), Vol. 25 No. 1, pp. 6-11.

Sirorei, E. and Fombad, M. (2019), "Knowledge management processes at St. Paul's university library in Kenya", South African Journal of Information Management, Vol. 21 No. 1, p. 8.

Skoglund, S. (2011), "Best practice recommendations for a corporate wiki in the research \& development department of software company", PhD diss. The University of Kansas.

Smith, J. (1994), Collective Intelligence in Computer-Based Collaboration, Lawrence Erlbaum Associates, Publishers, Hillsdale, NJ.

Smith, E.A. (2001), "The role of tacit and explicit knowledge in the workplace", Journal of Knowledge Management, Vol. 5 No. 4, pp. 311-321.

Spalding, H. and Wang, J. (2006), "The challenges and opportunities of marketing academic libraries in the USA: experiences of US academic libraries with global application”, Library Management, Vol. 27 Nos 6/7, pp. 494-504, doi: 10.1108/01435120610702477.

Stewart, T. (1997), Intellectual Capital: The New Wealth of Organizations, Doubleday/Currency, New York, NY.

Subnum, H. and Rowley, J. (2011), "Branding of UK public libraries", Library Management, Vol. 32 Nos 4/5, pp. 346-360. 
Swain, D.E. (2010), "A time-based model of collaboration for knowledge management and project management", (Chapter 7), in Kanti Srikantaiah, T., Koenig, M. and Hawamdeh, S. (Eds), Convergence of Project Management and Knowledge Management, Scarecrow Press, Lanham, MD.

Vorobyov, A., Pozdeev, P., Kruglova, N., Nogovitsyna, O. and Tokareva, P. (2019), "A unified methodology of strategic management and knowledge management model", TEM (Technology Education Management Informatics) Journal, Vol. 8 No. 2, pp. 554-563.

Wall, A., Kirk, R. and Martin, G. (2004), Intellectual Capital: Measuring the Immeasurable?, CIMA Publishing (Elsevier), Burlington, MA.

Wheetly, A. (2016), "Five of the coolest libraries for children in the US", WWW Books Tell You Why.com, June 29, 2016, available at: https://blog.bookstellyouwhy.com/five-coolest-libraries-for-children, (accessed 1 October 2018).

White, R.M. (1963), The School-Housed Public Library-a Survey, ALA, Chicago.

Wildemuth, B., (Ed.) (2017), Applications of Social Research Methods to Questions in Information and Library Science, 2nd ed, Libraries Limited, Westport, CT.

Wu, I.-L. and Hu, Y.-P. (2018), "Open innovation based knowledge management implementation: a mediating role of knowledge management design", Journal of Knowledge Management, Vol. 22 No. 8, pp. 1736-1756.

\section{Further reading}

Bergoc, A. (2012), "Challenge and change: three decades of joint use libraries in the city of Onkaparinga", South Australia. APLIS, Vol. 25 No. 3, pp. 116-119.

\section{Appendix 1. Issues list for analysis in summary forms and matrices (phase one)}

In the iterative process of qualitative data analysis, issues were summarized and then entered into matrices to be distilled into a list of significant issues and barriers to collaboration. The following shows the full list of issues and concerns from early documents and articles about determining the size and resources for the ImaginOn joint-use facility:

- Parking for downtown facilities;

- Economic concerns and budget changes for CML;

- CML goals for youth services;

- Location change for CML children's library;

- Deterioration of Main Library in Charlotte;

- Architecture and building plans (never done before);

- Creative goals for children's drama classes and theater performances;

- Long hours and pay for ImaginOn staff;

- Disconnect between county government and CML; and

- The impact of branding on ImaginOn.

Appendix 2. Primary communication participants and quotations (phase one)

Participants in Collaboration as identified in publication and public documents

- *Robert Cannon, executive director Public Library of Charlotte and Mecklenburg County (PLCMC);

- Bruce LaRowe, director of Children's Theater of Charlotte (CTC);

- Margaret Sullivan, Charlotte Mecklenburg Library (CML) children's librarian;

- *Karen Thompson Beach, director of community engagement for CML;

- Chris Bates, senior library manager;

- Andrew Komeda (pseudonym), consultant with Branding Initiative Co (Pseudonym);

- *Melanie Huggins, CML librarian and director during building; 
- Sarah Goldstein, marketing and communications specialist;

- Eugene Aubry, architect (building renovations);

- Don Palmer, interior design architect;

- Margaret Sullivan, interior design architect;

- Randy Akers, professor and researcher on branding and visual communications;

- Jack Hedge, architect;

- Geri Lynn Sponass, librarian;

- T. Fergusen (pseudonym), web graphics/visual communications designer;

- Ginger Shuler, former chief of youth services;

- *Lois Kilkka, ImaginOn manager; and

- Allen Poindexter, CTC artistic director.

*Sample quotations about innovation from 4 influential participants in Table B1 document the goals and communication required throughout the joint-use development project.

\section{Appendix 3. Timeline of events (phase one)}

Significant events during ImaginOn's early development:

- 1983 Bond referendum passes for library system;

- 1989 Open remodeled Main Library;

- 1989 Parking issue discussions (CML and CTC);

- 1990 Idea of a shared center for children's learning and theater formed;

- 1995 Joint task force formed (Charlotte and Mecklenburg County);

- 1996-1999 Additional bonds passed to build libraries;

- 1999 Core team for joint-use formed (Melanie Huggins, leader);

- 1999-2004 Core team develops feasible plan for joint-use library and theater;

- 2005-2007 Naming of "ImaginOn" with outside help and facility dedication;

- 2010-2011 Future of the Library Task Force (citizen task force) formed;

- 2012-2014 Mecklenburg County increased funding to CML; and

- 2018 Teen space established at main library as children aged out of ImaginOn.

\section{Table A1 Collected interviews: sample quotations on innovation}

\section{Sample quotes from collected interviews} Robert Cannon Karen TBeach Melanie Huggins Lois Kilkka

"Charlotte Mecklenburg being more independent could be more creative." (Roughen, 2012)
"We have done a great job branding ImaginOn," but that it branding as ImaginOn made raising funds more difficult because people don't recognize that it is a library: "A lot of donors taxpayers don't always realize that ImaginOn is a library [...] they think it is more like a children's museum." (Roughen, 2012)
The core team worked diligently "starting to get to know each other, getting to know each other's organizations, What they did, how we were different, how we were the same." (Roughen, 2012)

\author{
,
}

res

\section{The mission [CML and CTC]} developed, 'bringing stories to life through extraordinary experiences that challenge, inspire and excite young minds,' blended the library and theater experiences by incorporating written, spoken, visual and digital methods of expression. The project leadership also considered the complexities that arise when two venerated institutions maintaining their own corporate identities [collaborate] to create a seamless visitor experience (Kilkka, 2008) 
For a summary of historic events, see background of the CML at www.cmlibrary.org/about/ library-history and www.imaginon.org/about-imaginon:

- August 1997: Children's Theatre and the Public Library create the ImaginOn concept;

- November 1999: Voters approve bond funds for construction;

- October 2000: Hardy Holzman Pfeiffer of NY (now Holzman Moss) and Gantt Huberman of Charlotte selected as architects;

- December 2000: Launch of Programming Endowment Campaign led by Ken Lewis and Ed Shelton;

- March 2003: Groundbreaking; and

- October 2005: Grand Opening!.

\section{Appendix 4. Semi-structured interview questionnaire (phase two)}

\section{Semi-structured questionnaire on knowledge management at ImaginON}

Before you begin, please describe your role(s) with ImaginOn, Charlotte-Mecklenburg Libraries and Charlotte community or government:

Answer these 5, open-ended questions at you own pace:

1. (Communication Tools) When collaborating across library and theater organizations, do you

2. use (or have you used) any "tools," such as shared document reviews like Google Docs; or

3. use any communication technology, such as teleconferences, online meetings (SKYPE or WebEx), email distribution lists or social media (Facebook, Twitter or Google hangout)?

4. (Knowledge Collection) What "IC" or knowledge assets do you collect for ImaginOn that are:

- tangible business accounts and data (attendees at theater shows, books and media checked out and income from used book store or gift shop); and

- intangible information and knowledge that is shared or stored for access (opinions and thoughts)? (Note: you can include any knowledge sharing with patrons, volunteers or parents.\}

5. (Meetings) Do you hold regular or irregular meetings between library and theater staff? Are they in-person, such as in "The Round" room, for example, or electronic communications/social media or both?

1. (Project Reviews) Do you have post-project meetings or "after action reviews" to collect lessons learned and plan future strategies or events?

Is information saved as best practices or benchmarks?

2. (Experience) Please tell a "story" about a new process or space change at ImaginOn (for example, replacing the gift shop).

About the authors

Deborah E. Swain, PhD, is an Associate Professor in the School of Library and Information Sciences at North Carolina Central University in Durham, NC, and has over 20 years experience in business, education and managing information projects. Swain has also taught at UNC-Chapel Hill, NC State and Campbell University. She does research in knowledge management, health informatics (human patient simulators) and usability (user experience). She completed her doctorate in Information Science at the University of North Carolina at Chapel Hill (1999). She has an MA from UNC-CH in English and a BA from Duke 
University. She teaches graduate courses in information science, health informatics, human factors, data mining and knowledge management. She has worked as a systems engineer, information developer, consultant and project manager for corporations such as IBM, AT\&T and Bell Labs. She was conference chair of the ICKM 2020 (International Conference for Knowledge Management). Deborah E. Swain is the corresponding author and can be contacted at: dswain@nccu.edu

Patrick Roughen, $\mathrm{PhD}$, is an Associate Professor in the School of Library and Information Sciences at North Carolina Central University in Durham, NC. He was born and raised in Savannah, Georgia. He earned his law degree in 1996 from the University of Georgia and his PhD. in 2012 from the University of South Carolina, where he was a Laura Bush 21st Century Librarian Teaching and Research Fellow through the Institute of Museum and Library Services (IMLS). As an undergraduate, he was a National Institutes of Health research assistant at Woods Hole Oceanographic Institution. He obtained an MLIS, while working full time as an attorney in the law firm of the City Attorney of Savannah. He is a member of the State Bar of Georgia and is registered to practice before the United States Patent and Trademark Office.

For instructions on how to order reprints of this article, please visit our website: www.emeraldgrouppublishing.com/licensing/reprints.htm

Or contact us for further details: permissions@emeraldinsight.com 